\title{
Message from the WGO President
}

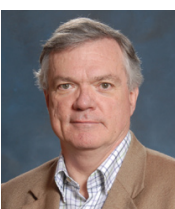

\section{Eamonn M.M. Quigley, MD}

President, World Gastroenterology Organisation; Professor of Medicine and Human Physiology, Alimentary Pharmabiotic

Center, University College Cork, Cork, Ireland

These are strange and difficult timesthe entire world is facing considerable financial challenges, while the issues of conflict, strife, starvation, and climate change have also not departed. Regrettably, health care tends to get short shrift in straitened circumstances and, within health care, priority is often given to the more acute and "dramatic" illnesses, while common, important, debilitating, but "unexciting" disorders (among which many of the most common digestive disorders rank), and the many patients who suffer from them, are ignored. This is not only unfortunate but also short-sighted, given the impact of these conditions on the young and active during what should be the most productive years of their lives.

It is most appropriate, therefore, that the World Gastroenterology Organisation (WGO) has chosen irritable bowel syndrome (IBS) as its theme for World Digestive Health Day 2009. This is truly a global disorder that affects millions worldwide, many of whom suffer in silence. The true importance of IBS in gastroenterology, medicine, and public health is amply and vividly illustrated by the tremendous response from national societies around the globe to this topic. IBS has proven to be a galvanizing World Digestive Health Day theme for medical practitioners, patients, and the public alike. WGO will be playing a truly global role on World Digestive Health Day-energizing member societies, supporting their activities, and generating supportive materials in a most collaborative manner. World Digestive Health Day on 29 May 2009, and indeed the entire year, will bring IBS into rightful prominence and will hopefully promote a better understanding of the condition and lead to progress in diagnosis and management.

The "global crisis" presents challenges to WGO. As each nation strives to address its own economic and social problems, global issues fade into the gloom, and funding becomes ever more difficult to source for programs such as those that WGO supports around the world (Train the Trainers, Training Centers, Global Guidelines, International Digestive Cancer Alliance, Outreach). It is most appropriate that

Continued on Page 4

\section{THIS ISSUE}

\section{Cancer of the exocrine pancreas} René Lambert \& Robert C. Kurtz

\section{WGO and ACG Global Collaboration Agreement Amy Foxx-Orenstein}

\section{World Digestive Health Day}

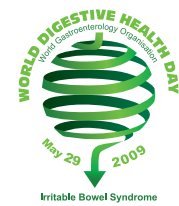

Irritable bowel syndrome: a global perspective

World Digestive Health Day Events Around the World 
01

Message from the WGO President

Eamonn M.M. Quigley

03

Message from the Editor

John Baillie

Scientific news

05

Cancer of the exocrine pancreas

René Lambert,

Robert C. Kurtz

11

How much

fluid should be given during the initial management of acute pancreatitis?

Nison Badalov,

Scott Tenner

13

Management of autoimmune pancreatitis:

a review of medical therapy

Ashraf Saleemuddin, William R. Brugge

\section{4}

What do we know about IBS in Mexico?

Max Schmulson

26

Current

challenges in

diagnosing and

treating IBS:

Per Olav Vandvik

30

Interview with

Professor

Zaigham Abbas:

IBS in Asia

32

Irritable bowel

syndrome:

a global perspective

35

Gastroenterology

on the Internet:

IBS and PubMed

Justus Krabshuis

GASTRO 2009

38

GASTRO 2009

— the place to be

Michael Farthing
19

TTT Trial Design

Workshop

Jim Toouli

20

WGO and ACG

Global Collaboration Agreement

Amy Foxx-Orenstein

21

Endoscopy workshop in Ghana

Mark Topazian

Personality Corner

40

Interview with

David Carr-Locke

42

Great mentors

Steven Silvis and Jack Vennes

John Baillie

43

Interview with Tom Finn, President of Global Health Care for Procter \& Gamble

\section{Vol.14, Issue 1}

Editor John Baillie Managing editor Molly Fassbender Design Milkdesign Studio

Editorial office WGO Executive Secretariat, Medconnect $\mathrm{GmbH}$,

Bruennsteinstr. 10.81541 Munich, Germany

Email info@worldgastroenterology.org 


\section{Message from the Editor}

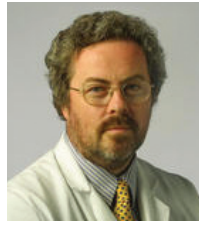

John Baillie, B. Sc (Hons), MB,

Ch.B, FRCP, FASGE, FACG

Wake Forest University Health Sciences

Winston-Salem, North Carolina, USA
Welcome to the second electronic edition of World Gastroenterology News! Our first issue was uniformly well-received. Emboldened by this positive feedback, we are exploring the possibilities for web-based learning opportunities. Keep a look-out for these new sections-such as embedded videos demonstrating new proceduresin the upcoming issues.

It is no accident that the Scientific Section of this issue of WGN has a distinctly pancreatic "flavor." As a card-carrying pancreatologist, I make no apologies for three articles on my favorite subject! Professors René Lambert and Robert Kurtz have contributed a detailed review of tumors of the exocrine pancreas. Clearly, the most vexing is adenocarcinoma of the pancreas, which stands almost alone amongst gastrointestinal malignancies as being a cancer with little hope of cure. When so many other once-fatal cancers are now eminently treatable, and often curable, why has pancreatic cancer remained such a predictable killer? Until recently, pancreatic cancer has not been a disease attracting charitable funding (compare it, for example, to breast cancer, childhood leukemia and, especially, AIDS). Deaths from pancreatic cancer among celebrities (such as "Bonanza" actor Michael Landon and Italian tenor Luciano Pavarotti) and news of others living with the disease (e.g., U.S. Supreme Court Judge Ruth Bader Ginsberg and actor Patrick Swayze) have spiked public interest, but a concerted effort and major research funding will be needed to "crack" this particular killer. Inadequate intravenous hydration is the silent killer in patients with severe acute pancreatitis (SAP), contributing to pancreatic necrosis, kidney failure, and other systemic manifestations of the disease. Dr. Scott Tenner of the State University of New York has been a leading advocate of aggressive intravenous hydration in these cases. Dr. Tenner and his colleague Dr. Badalov outline for us the fluid regimen that should be used in cases of predicted and actual SAP-information that (to the best of my knowledge) has not previously been promulgated in journal form. Finally, pancreatologist extraordinaire Dr. Bill Brugge and his colleague Dr. Saleemuddin from the Massachusetts General Hospital in Boston review the hot topic of medical therapy for autoimmune pancreatitis.

We intend to have future Scientific Sections dedicated to particular diseases and management themes. I would welcome readers' suggestions for subjects we should look at.

Irritable bowel syndrome (IBS) is "big" this year, and in recognition of that fact, we are pleased to bring you four papers on the subject. Dr. Per Olav Vandvik, Associate Professor of Medicine at the University of Oslo, discusses current challenges in the diagnosis and treatment of IBS. Dr. Max Schmulson of the Universidad Nacional Autónoma de México tells us "what we know about IBS in Mexico." Finally, the WGO librarian, Justus Krabshuis, continues his outstanding series on gastroenterology on the Internet, with an overview of how to search intelligently for IBS-related publications. Last, but by no means least, Irritable Bowel Syndrome: A Global Perspective presents the highlights of WGO's Global Guideline for IBS.

The year 2009 seems to be whizzing by, and in the blink of an eye it will be the end of the year and time for the next World Congress of Gastroenterology, to be held in London. In this issue of WGN, Dr. Michael Farthing assures us that this will be an outstanding international meeting, with something for everyone, including a live endoscopy course featuring procedures beamed in from no less than three countries!

Under the heading "Great Mentors," I have kicked off a little series on the role of mentors in gastroenterology. Mentors for young researchers and for clinical and procedural trainees in particular are becoming an endangered species—let's help preserve the species by honoring them. I have already received invited contributions to this series that will appear in future issues of $W G N$, but I would be very happy to have more. Had a great mentor, or mentors? Let's hear about her or him!

And finally, I would greatly appreciate feedback from our readers about the current format and content of WGN. Now that we are electronic, (almost) anything is possible! Let me know what you would like to see in the journal. 


\section{Message from the WGO President}

\section{Continued from cover}

WGO has therefore established the WGO Foundation to raise funds and secure the future of its programs. We would ask all of you, as individuals, members of national societies, or as acquaintances of funding agencies or philanthropists, to support the WGO Foundation. Our future is your future!

Despite these challenges, WGO has been even more active: a new TTT program on "Trial Design" was most successfully presented in the beautiful city of Dubrovnik, Croatia; a full TTT will take place in Santiago, Chile in September; IDCA will present or participate in several important programs; two new guidelines are about to appear; and major equipment donations were delivered to our training centers in Suva (Fiji) and Ribeirão Prêto (Brazil). WGO has not reneged and will not renege on its mission and will continue to pursue its goals with as much vigor and rigor as ever. Join us in these efforts!

Of course, the pinnacle of our year will be GASTRO 2009 in London in November, which will represent the culmination of a remarkable collaboration between WGO, UEGF, OMED, and the British Society of Gastroenterology to present a world congress with a European flavor in a British atmosphere. The excitement around GASTRO 2009 worldwide is really palpable and-having seen the program and knowing of all the work that has gone into developing it, including the working parties, Young Clinicians' Program, and the various named lectures (distinctive features of world congresses) - I know that "this excitement is fully justified. Come to London in November. You will be richly rewarded!

Eamonn M.M. Quigley WGO President 2005-2009

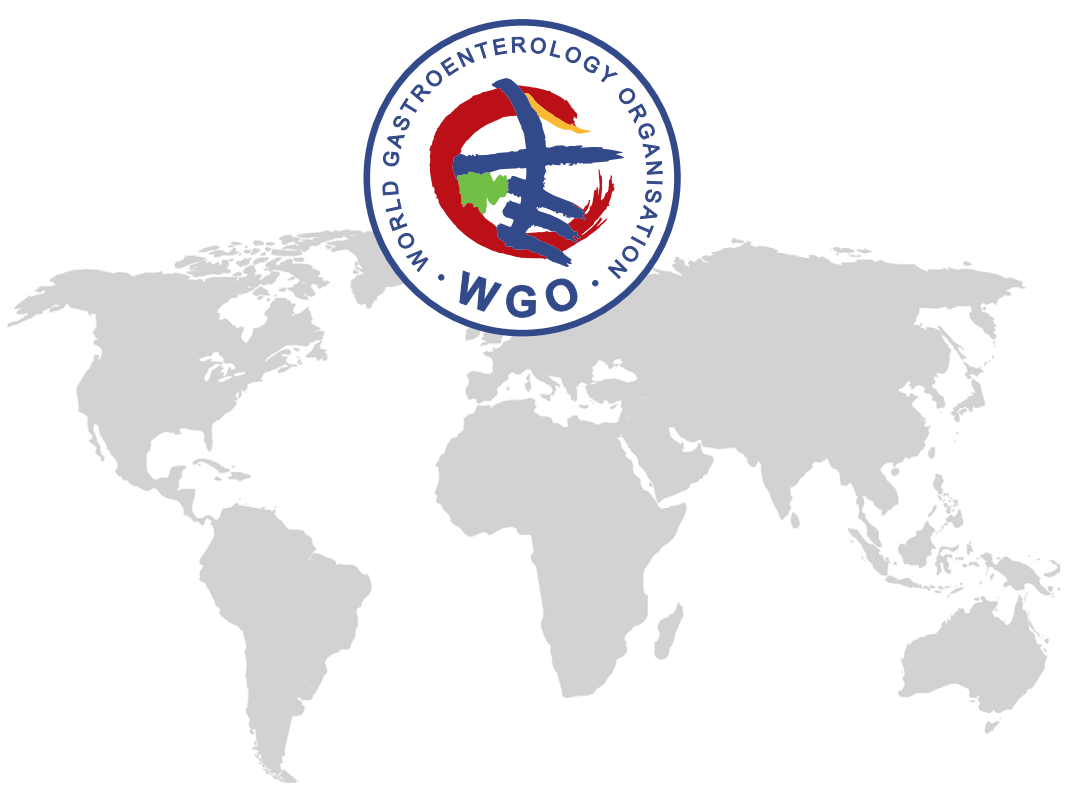




\section{Cancer of the exocrine pancreas}
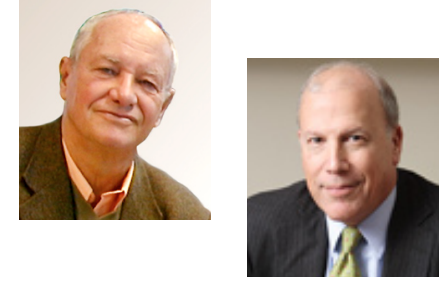

\section{Introduction}

Pancreatic tumors are classified on the basis of cell differentiation and immunostaining. Cancer of the exocrine pancreas develops from ductal epithelial cells or from acinar cells.

Ductal adenocarcinomas represent more than $90 \%$ of all pancreatic carcinomas. Other neoplastic ductal lesions with a variable risk of malignancy include areas of flat hyperplasia in the ductal epithelium, with successive mutations of KRAS, $p 53, p 16, D P C 4$, and three categories of cystic neoplastic lesion: mucinous cystic adenomas, intraductal papillary mucinous neoplasms (IPMNs), and serous cystadenomas, which have a very low risk for malignancy.

Nonductal adenocarcinomas develop from the acinar cells and are relatively rare. In acinar cell carcinoma, acinar differentiation is confirmed by zymogen granules positive for periodic acid-Schiff and immunostaining for trypsin; the tumor is usually large at detection (around $10 \mathrm{~cm}$ ) and mutations of the $\beta$-catenin gene are frequent. Pancreatoblastoma is another highly malignant nonductal carcinoma, which occurs in children under the age of 10 years. The genetic alterations of ductal carcinoma are not present, and alteration in the $\beta$-catenin pathway is frequent. Solid pseudopapillary neoplasms, which are borderline lesions with low-grade malignancy, are also classified in this group.

Endocrine pancreatic tumors, including multiple endocrine neoplasia type 1 (MEN-1), represent a third
René Lambert, MD and Robert C. Kurtz, MD

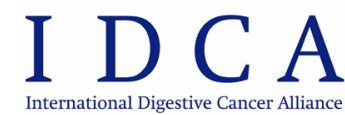

René Lambert, MD, IARC, Lyons, France

Robert C. Kurtz, MD, Memorial Sloan-Kettering

Cancer Center, New York, New York, USA

group derived from the islets of Langerhans. Misclassification may occur in these cases in the presence of mixed exocrine-endocrine tumors, with combinations such as acinarendocrine or acinar-ductal-endocrine.

Tumors of the pancreas are also classified on the basis of their morphology—solid or cystic. Solid tumors include ductal adenocarcinoma, acinar carcinoma, and borderline lesions: solid pseudopapillary tumor and endocrine neoplasia. Cystic pancreatic masses are increasingly being recognized, as a direct consequence of the more widespread use of imaging technology. Nonneoplastic and inflammatory cystic massespseudocysts-are of course by far the most common pancreatic cystic lesions, associated with a history of pancreatitis. Cystic neoplasms, which represent $10-15 \%$ of cystic masses of the pancreas, include serous cystadenomas, mucinous cystic neoplasms, and intrapancreatic mucinous neoplasms (IPMNs).

Finally, some solid tumors may have a cystic morphology; this occurs in pseudopapillary neoplasm, acinar carcinoma (which is then classified

\begin{tabular}{|l|l|}
\hline Region & Cases (n) \\
\hline North America & 34900 \\
\hline South America & 13400 \\
\hline Central America & 4200 \\
\hline Africa (5 areas) & 7100 \\
\hline Europe (with Russia) & 78000 \\
\hline Asia (with Japan) & 91000 \\
\hline
\end{tabular}

as an acinar cystadenocarcinoma), and some endocrine-secreting tumors (e.g., insulinoma, gastrinoma, glucagonoma).

\section{The burden of \\ pancreatic cancer}

The epidemiology and burden of pancreatic cancer relate to ductal adenocarcinoma-a dismal disease with a poor prognosis and early lymphatic and hematogenic dissemination. At the time of diagnosis, less than $10 \%$ of the lesions present as localized tumors, and the patients 5 -year survival is still not over $5 \%$. In the International Agency for Research on Cancer (IARC) Globocan 2002 database, the worldwide burden of pancreatic cancer for the year 2005 is estimated at 232,000 new cases and 227,000 deaths [1]. Of the new cases, 125,000 affect men and 107,500 women. In the same database, cancer of the pancreas ranks twelfth for the frequency of cancer and eighth for mortality.

Incidence. The estimated numbers of annual cases occurring in various regions are shown in Table 1, which is derived from the IARC database [1]. Geographic variations in the
Table 1. Estimated numbers of incident cases of cancer of the pancreas (both sexes) occurring in 2002 in various regions of the world, from the International Agency for Research on Cancer (IARC) Globocan 2002 database [1]. 
(1a) Incidence of Pancreas cancer: ASR (World) - Male (All ages)
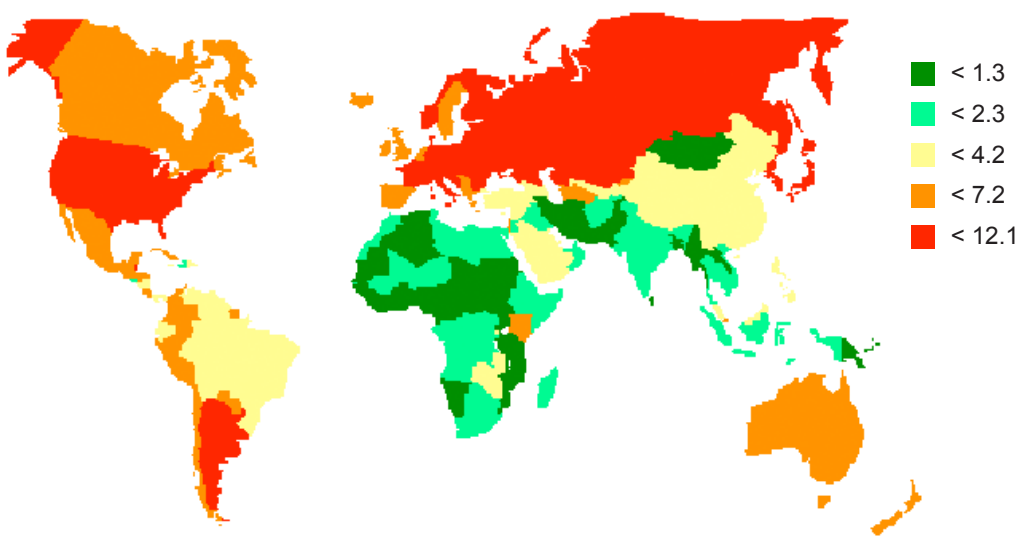

(1b) Incidence of Pancreas cancer: ASR (World) - Female (All ages)
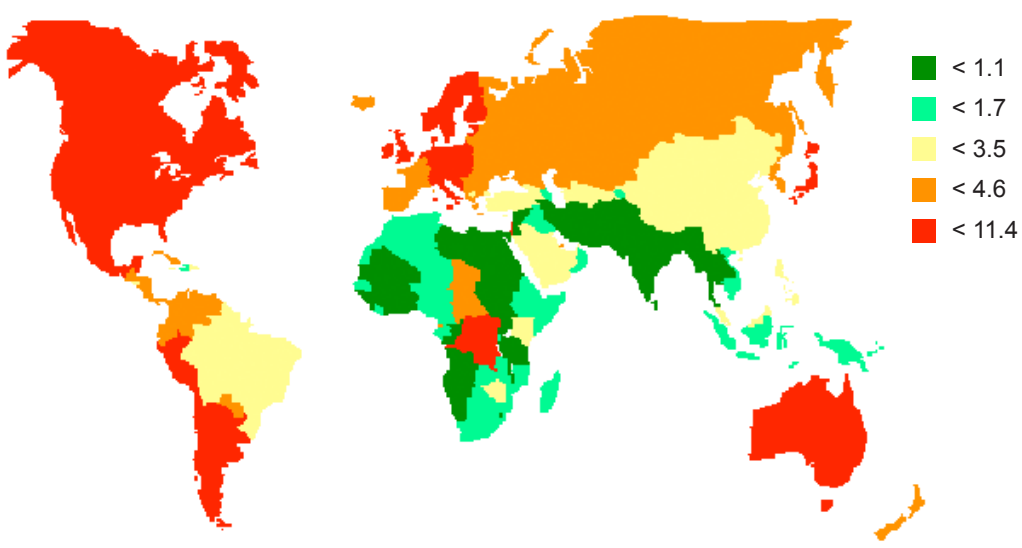

Fig 1. Regional variations in the age-adjusted incidence per 100,000 of cancer of the pancreas presented in a world map, for men (1a) and women (1b). (From the International Agency for Research on Cancer Globocan 2002 database) [1].

estimated age-adjusted incidence per 100,000 (age-standardized rate, ASR) for pancreatic cancer are shown for men and women in Fig. 1 from the same database. The figures are higher in North America, European countries and Russia, Japan, and Argentina, and much lower in developing countries in Africa, as well as in India and China. The observed ASR for pancreatic cancer in cancer registries is shown for some countries around the world in Table $\mathbf{2}$ and is slightly lower in women than in men [2]. In the USA, slight differences in the ASR incidence are shown in the Surveillance Epidemiology and End Results (SEER) registries for different ethnic groups (Table 3) [3]. The highest values occur in persons of African origin and the lowest in those with Native American and Asian ethnic backgrounds.
Mortality. A comparison between the estimated incidence and mortality from pancreatic cancer is also available in the IARC database [1] and is shown for three countries in Table 4. The annual number of deaths is equivalent to the annual number of new cases; this confirms that the average survival is not more than 1 year from diagnosis. The age-adjusted mortality rate of per 100,000 in men and in women is very similar to that of ASR incidence, as shown in Table 3; the difference is minimal in men but more marked in women.

Survival. The prognosis with pancreatic carcinoma is very poor, and the relative 5-year survival in 83 cancer registries and 23 European countries in the EUROCARE-4 study was $5.5 \%$ for both sexes in the period 1995-99 [4]. Time trends in the 5-year relative survival have been analyzed for the period 1975-2000 in the SEER registries and are shown in Table 5; a slight improvement is evident, with figures increasing from $3.6 \%$ to $5.2 \%$ in men and $2.1 \%$ to $5.4 \%$ in women [3]

\section{Causal factors in sporadic pancreatic cancer}

The identification of environmental factors in carcinogenesis is of major help for developing cancer prevention policies. Unfortunately, most casecontrol and cohort studies conducted for pancreatic cancer have proved inconclusive.

Smoking. This is the only significant promotor factor. In a meta-analysis conducted recently by lodice et al. [5], the risk of pancreatic cancer is increased at $\mathbf{1 . 7 4}$ for current smokers and 1.2 for former smokers. Overall, smoking causes a $75 \%$ increase in risk of pancreatic cancer. Taking into account the proportion of smokers in the population, the attributable risk of smoking for pancreatic cancer is around $20 \%$.

Alcohol, coffee, tea. The data from two very large cohort studies in the USA, the Health Professionals FollowUp Study and the Nurses' Health Study, with 1,907,222 person-years of followup, have been revised by Michaud et al. [6]. They do not support any association between coffee or alcohol intake and the risk of pancreatic cancer. A similar negative conclusion emerged from the European Prospective Investigation into Cancer and Nutrition (EPIC) and from the Collaborative Cohort Study for Evaluation of Cancer Risk (JACC study) in Japan. The data in the populationbased cohort study in Japan (JPHC study) do not support any impact of green tea consumption on the risk of pancreatic cancer.

Physical activity and obesity. Occupational or leisure-time physical activity has been associated with a lower risk for pancreatic cancer in several studies, but a systematic review of the literature has not provided strong evidence for an association. In a metaanalysis conducted by Larsson et al. on the role of obesity, a slight association 


\begin{tabular}{|l|l|l|}
\hline & Men & Women \\
\hline Chile: Valdivia & 4.2 & 3.8 \\
\hline USA: SEER, 14 registries & 7.9 & 5.9 \\
\hline China: Hong Kong & 4.5 & 3.1 \\
\hline China: Shanghai & 7.5 & 5.3 \\
\hline Japan: Osaka & 9.3 & 5.4 \\
\hline Korea: Seoul & 8.7 & 5.0 \\
\hline Denmark & 7.8 & 6.6 \\
\hline France: Calvados & 7.6 & 5.2 \\
\hline Italy: Veneto & 9.9 & 7.0 \\
\hline
\end{tabular}

Table 2. Observed age adjusted incidence rate per 100,000 of cancer of the pancreas in cancer registries from various countries during the period 1998-2002 (from Cancer Incidence in Five Continents, vol. 9, Lyons: IARC, 2007; IARC Scientific Publications no. 160) [2]. was observed, with an estimated relative risk of pancreatic cancer (per $5 \mathrm{~kg} / \mathrm{m}^{2}$ ) of 1.12 [7].

Fruit and vegetables. Case-control studies have suggested that higher consumption of fruit and vegetables, including citrus fruits, is associated with a lower risk of pancreatic cancer, but cohort studies do not support this association. No protection against pancreatic cancer from the consumption of fruit and vegetables was demonstrated in the very large European prospective study cohort (EPIC).

Sugar. It has been hypothesized that hyperglycemia, hyperinsulinemia, and insulin resistance are involved in the development of pancreatic cancer, but epidemiologic studies on the role of added sugar or sugar-sweetened foods and beverages are inconclusive. In a large study with a 7.2-year follow-up conducted in the USA, consumption of sugar was not associated with pancreatic cancer.

Diabetes. Two types of diabetes are associated with pancreatic diseases. Hyperinsulinemia and peripheral insulin resistance (type 2 diabetes) are the prevailing diabetic traits in pancreatic cancer, whereas reduced islet cell mass and impaired insulin secretion

\begin{tabular}{|l|l|l|l|l|}
\hline & \multicolumn{3}{l}{ Men } & Women \\
\hline & Incidence & Mortality & Incidence & Mortality \\
\hline All ethnic groups & 13.0 & 12.2 & 10.3 & 9.3 \\
\hline White & 13.0 & 12.1 & 10.0 & 9.0 \\
\hline Black & 16.2 & 15.4 & 14.3 & 12.4 \\
\hline Asian & 10.1 & 8.0 & 8.2 & 6.9 \\
\hline Native Americans & 10.9 & 8.6 & 8.2 & 7.2 \\
\hline Hispanic & 10.9 & 9.1 & 10.3 & 7.6 \\
\hline
\end{tabular}

Table 3. Observed age-adjusted incidence and mortality per 100,000 of cancer of the pancreas by sex and ethnic group in cancer registries in the USA (2001-2005 period, from 17 Surveillance Epidemiology and End Results registries) [3].

\begin{tabular}{|l|l|l|}
\hline Country & Cases $(n)$ & Deaths $(n)$ \\
\hline France & 5300 & 7250 \\
\hline USA & 31650 & 30300 \\
\hline Japan & 19900 & 20100 \\
\hline
\end{tabular}

Table 4. Comparison of the estimated numbers of incident cases and of deaths from cancer of the pancreas (both sexes) occurring in 2002 in three countries, from the International Agency for Research on Cancer (IARC) Globocan 2002 database [1].

\begin{tabular}{|l|l|l|}
\hline & Men & Women \\
\hline 1975 & 3.6 & 2.1 \\
\hline 1985 & 2.6 & 3.9 \\
\hline 1995 & 3.1 & 4.5 \\
\hline 2000 & 5.2 & 5.4 \\
\hline
\end{tabular}

Table 5. Time trends in the 5-year relative survival by sex in cancer registries in the USA (1975-2000 period, from nine Surveillance Epidemiology and End Results registries) [3]. occur in chronic pancreatitis (type 1 diabetes). It has been suggested that pancreatic cancer causes diabetes. Recognition of new-onset diabetes as an early manifestation of pancreatic cancer could lead to the diagnosis of early-stage pancreatic cancer. Newonset hyperglycemia could be used as a screening tool to identify people with asymptomatic pancreatic cancer; however, the success of this method depends on our ability to differentiate pancreatic cancer-associated diabetes from the more common type 2 diabetes.

\section{Hereditary factors}

The occurrence of at least two cases of pancreatic cancer in first-degree relatives of a family suggests a familial aggregation of cases. This situation is present in almost $10 \%$ of cases and has analyzed by Geenen and Kaul in another issue of WGN. Pancreatic cancer can occur in genetic hereditary syndromes for other categories of tumor, with an identified germline mutation: BRCA1/BRCA2 gene mutations and breast cancer, mismatch repair gene ( $M L H 1, M S H 2)$ mutations and hereditary nonpolyposis colorectal cancer (HNPCC) syndrome, STK-11/LKB1 gene mutation, and Peutz-Jeghers syndrome, CDKN2A gene mutation and the familial atypical multiple mole-melanoma (FAMMM) syndrome, in which melanomas are associated with benign moles. Pancreatic cancer also occurs in the hereditary pancreatitis syndrome, in which mutations in SPINK1/PRSS1 genes play a role. This syndrome is characterized by recurrent attacks of acute pancreatitis. Finally, aggregation of pancreatic cancer occurs in the familial pancreatic cancer syndrome, where the mutation is unknown. Familial pancreatic cancer can be defined as an inherited predisposition based on family clustering, with two or more blood relatives with pancreatic adenocarcinoma of ductal origin. As shown by Hruban et al. [8], a family history of pancreatic cancer is present in about $10 \%$ of patients with this disorder. 
Several registries are collecting data on hereditary pancreatic cancer. The EUROPAC registry is based in Liverpool, United Kingdom, and there are about a dozen hereditary pancreatic cancer registries established in the USA, including those at the Johns Hopkins Medical Center and the Mayo Clinic. A Familial Pancreatic Tumor Registry has been established at the Memorial Sloan-Kettering Cancer Center in New York. Over 1500 individuals have been recruited to the registry, including pancreatic cancer patients with multiple affected relatives, healthy individuals with multiple affected relatives, healthy controls, patients with sporadic pancreatic cancer, and patients with IPMNs. Because of the association of BRCA mutations and pancreatic cancer, individuals with a BRCA1 or BRCA2 mutation and a family history of pancreatic cancer are also recruited. The registry has served as a resource for a number of ongoing studies, including epidemiology of pancreatic cancer, screening at-risk relatives for pancreatic neoplasia, and genome-wide association studies.

\section{Premalignant neoplastic lesions}

Pancreatic intraepithelial neoplasia is a precursor of ductal carcinoma. In surgical specimens, areas of flat hyperplasia with columnarization of ductal epithelium and ductal papillary hyperplasia are found adjacent to invasive carcinoma. The progression to malignancy is accompanied at an early stage by mutations in the KRAS oncogene, followed by mutations of p53, p16, and DPC4/ SMADD4 tumor suppressor genes.

Benign cystic neoplasms are tumors with ductal differentiation that have a variable potential for malignancy. Serous cystadenomas (SCAs) occur mainly in middle-aged women and account for $30 \%$ of primary cystic neoplasms; depending on their size, they are classified as microcystic or macrocystic. They are usually benign; progression to serous cystadenocarcinoma is very rare. Mucinous cystic neoplasms (MCNs) occur predominantly in middle-aged women and account for $45 \%$ of primary cystic neoplasms. Their appearance is often that of a cyst within a cyst, without communication with the pancreatic duct. The presence of ovarian stroma in the tumor is strongly suggestive of the diagnosis. They are classified as borderline neoplastic lesions, which progress in 5-35\% of cases to mucinous cystadenocarcinomas. Intraductal papillary mucinous neoplasms (IPMNs) occur more often in men and account for $25 \%$ of primary cystic neoplasms. Their appearance is that of a grape with cysts. IPMNs arise from the main pancreatic duct or from its branches, and communicate with the duct. IPMNs arising from the main pancreatic duct carry a higher risk of malignancy (60$90 \%$ ) than those arising from collateral branches (around 5\%).

Solid pseudopapillary neoplasms are tumors with nonductal differentiation, composed of partially encapsulated sheets of polygonal cells with a cystic morphology. They stain positive for the markers vimentin and CD10, and are negative for ductal and endocrine markers. Solid pseudopapillary neoplasms are more frequent in women and are classified as borderline malignant lesions.

\section{Diagnosis}

The dramatic progress in radiographic imaging and endoscopic exploration of the pancreas has led to a much more reliable classification of cystic lesions of the pancreas and made it possible to distinguish malignant or benign neoplastic lesions from pancreatitis. Percutaneous biopsies of a solid pancreatic mass performed with ultrasound or computed tomography (CT) guidance provide tissue specimens for histology. Overall, there has been some progress in the early detection of pancreatic cancer, but survival after treatment for pancreatic cancer remains depressingly poor.

\section{Imaging}

Transabdominal ultrasound, which outside the U.S. is still the basic screening procedure, may detect dilation of the biliary duct and even of the main pancreatic duct (of Wirsung), but the pancreas itself is often poorly visible due to gas in overlying bowel segments. The procedure is very operator-dependent. High-resolution helical CT scanning of the abdomen with intravenous contrast enhancement is now widely available. The size and the location of cystic neoplasms in the head, body, or tail of the pancreas can be determined, as well as the presence of intracystic masses or mural nodules and communication with the pancreatic duct. Serous cystic adenomas often show a honeycomb pattern, with multiple, small cysts within a large cyst and a central stellar scar that may calcify. Mucinous cystic neoplasms are often large and multilocular; IPMNs produce the characteristic image of a bunch of grapes containing numerous small cysts, communicating with a dilated pancreatic duct or its branches; mural nodules or intracystic masses are frequent. Another recently introduced imaging test is magnetic resonance cholangiopancreatography (MRCP). Single-shot, fast spin-echo MR images can detect small pancreatic cysts with more precision than abdominal ultrasound or CT scanning.

\section{Endoscopy}

Endoscopic retrograde cholangiopancreatography (ERCP) is the most sensitive technique for detecting a communication between a cyst and the pancreatic ducts occurring in IPMN. The diagnosis is also suggested when mucus is seen leaking from a patulous papilla. Pancreatoscopy for direct observation of the tumoral lesions in the pancreatic duct is now possible using small-caliber flexible endoscopes (miniscopes).

Endoscopic ultrasonography (EUS) is increasingly available for the diagnosis and management of pancreatic neoplastic lesions. As an alternative to conventional echo endoscopes, flexible high-frequency $(20-\mathrm{MHz})$ catheter probes can be introduced through the working channel of an endoscope. In 
the presence of mucinous neoplasms, malignancy can be predicted with an accuracy of $50 \%$ with EUS, based on the following criteria: size greater than $2 \mathrm{~cm}$, pancreatic duct dilation, wall calcifications, and masses or mural nodules. In specialized centers, EUS is used to aspirate cyst fluid using fineneedle aspiration (FNA). The aspirated fluid is evaluated for cytology, with cuboidal cells staining for glycogen, in serous cysts and columnar cells staining for mucin in mucinous cysts. Two biological markers are helpful for differentiating between mucinous and serous neoplastic lesions: amylase activity is low in serous neoplasms and high in mucinous ones; the carcinoembryonic antigen (CEA) concentration is below the threshold value of $192 \mathrm{ng} / \mathrm{mL}$ in serous neoplasms and above that value in mucinous ones.

\section{Screening and surveillance}

Guidelines recommend surveillance using repeated imaging procedures (CT, MRI, EUS) in individuals diagnosed as having an IPMN, which is associated with a significant risk of malignant development.

No screening strategy for early detection of sporadic pancreatic cancer is recommended in asymptomatic persons. On the other hand, screening and surveillance at regular intervals are recommended for those with an increased risk for pancreatic ductal adenocarcinoma. This applies to inherited genetic syndromes, hereditary pancreatitis, and familial pancreatic cancer. In the USA, pancreatic cancer has a low prevalence; however, members of families with familial pancreatic cancer (FPC) are an identifiable at-risk group for whom screening could be both feasible and beneficial. A screening program was started at the Memorial SloanKettering Cancer Center in 2002, using cross-sectional imaging as the primary screening tool, followed by endosonography if any pancreatic abnormalities were found. IPMN was the most common pancreatic lesion found in the FPC population and may very well represent the pancreatic cancer precursor lesion in this population. This finding is similar to what was reported by Canto et al. [9] from Johns Hopkins in their FPC screening study. Clearly, it is too early to determine the long-term benefit from screening members of FPC families.

\section{References}

1. Ferlay J, Bray F, Pisani P, Parkin DM. Globocan 2002: cancer incidence, mortality and prevalence worldwide. IARC CancerBase No. 5, version 2.0. Lyons: IARC Press, 2004.

2. Curado MP, Edwards B, Shin HR, et al., editors. Cancer incidence in five continents, vol. 9. Lyons: IARC, 2007 (IARC Scientific Publications, no. 160).

3. Surveillance, Epidemiology, and End Results (SEER) program (public use). http:// seer.cancer.gov/index.html.
4. Berrino F, De Angelis R, Sant M, and EUROCARE Working group. Survival for eight major cancers and all cancers combined for European adults diagnosed in 1995-99: results of the EUROCARE-4 study. Lancet Oncol 2007;8:773-83.

5. lodice S, Gandini S, Maisonneuve P, et al. Tobacco and the risk of pancreatic cancer: a review and meta-analysis. Langenbecks Arch Surg 2008;393:535-45.

6. Michaud DS, Giovannucci E, Willett WC, et al. Coffee and alcohol consumption and the risk of pancreatic cancer in two prospective United States cohorts. Cancer Epidemiol Biomarkers Prev 2001;10:429-37.
7. Larsson SC, Orsini N, Wolk A. Body mass index and pancreatic cancer risk: a metaanalysis of prospective studies. Int J Cancer 2007;120:1993-8.

8. Hruban RH, Petersen GM, Goggins M, et al. Familial pancreatic cancer. Ann Oncol 1999;10(Suppl 4):69-73.

9. Canto MI, Goggins M, Hruban RH, et al. Screening for early pancreatic neoplasia in high-risk individuals: a prospective controlled study. Clin Gastroenterol Hepatol 2006;4:766-81. 


\section{Further Reading}

Bae JM, Lee EJ, Guyatt G. Citrus fruit intake and pancreatic cancer risk: a quantitative systematic review. Gastric Cancer 2008;11:23-32.

Fitzgerald TL, Hickner ZJ, Schmitz M, et al Changing incidence of pancreatic neoplasms: a 16-year review of statewide tumor registry. Pancreas 2008;37:134-8.

Geenen JE, Kaul V. Familial pancreatic cancer: an update. World Gastroenterology News [in press].

Hart AR, Kennedy H, Harvey I. Pancreatic cancer: a review of the evidence on causation. Clin Gastroenterol Hepatol 2008;6:275-82.

Ho JM, Darcy SJ, Eysselein VE, et al. Evolution of fine needle aspiration cytology in the accurate diagnosis of pancreatic neoplasms. Am Surg 2007;73:941-4.

Hutchins GF, Draganov PV. Cystic neoplasms of the pancreas: a diagnostic challenge. World J Gastroenterol 2009;15:48-54.

Klimstra DS. Nonductal neoplasms of the pancreas. Mod Pathol 2007;20(Suppl 1): S94-112.
Kurtz RC, Ludwig E, Simon J, et al.

Pancreatic screening program for familial high risk individuals [abstract]. Gastroenterology 2007;132(Suppl 2):A-119.

Lachter J, Cooperman JJ, Shiller M, et al. The impact of endoscopic ultrasonography on the management of suspected pancreatic cancer-a comprehensive longitudinal continuous evaluation. Pancreas 2007:35:130-4.

Parkin DM, Whelan SL, Ferlay J, et al., editors. Cancer incidence in five continents, vol. 8. Lyons: IARC, 2002 (IARC Scientific Publications, no. 155).

Rubenstein JH, Scheiman JM, Anderson MA. A clinical and economic evaluation of endoscopic ultrasound for patients at risk for familial pancreatic adenocarcinoma. Pancreatology 2007;7:514-25.

Sahani DV, Lin DJ, Venkatesan AM, et al. Multidisciplinary approach to diagnosis and management of intraductal papillary mucinous neoplasms of the pancreas. Clin Gastroenterol Hepatol 2009;7:259-69.
Sahni VA, Mortele KJ. Magnetic resonance cholangiopancreatography: current use and future applications. Clin Gastroenterol Hepatol 2008;6:967-77.

Seo S, Doi R, Machimoto T, et al. Contribution of $18 \mathrm{~F}$-fluorodeoxyglucose positron emission tomography to the diagnosis of early pancreatic carcinoma. J Hepatobiliary Pancreat Surg 2008;15:634-9.

Shi C, Daniels JA, Hruban RH. Molecular characterization of pancreatic neoplasms. Adv Anat Pathol 2008;15:185-95.

Singh M, Maitra A. Precursor lesions of pancreatic cancer: molecular pathology and clinical implications. Pancreatology 2007:7:9-19.

Zhang XM, Mitchell DG, Dohke M, et al. Pancreatic cysts: depiction on single-shot fast spin-echo MR images. Radiology 2002;22:547-53.a 


\section{How much fluid should be given during the initial management of acute pancreatitis?}

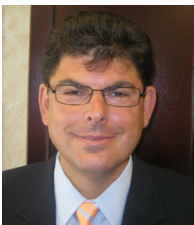

\author{
Nison Badalov, MD and Scott Tenner*, MD ("photo)
}

Division of Gastroenterology, Maimonides Medical Center, State University of New York Health Sciences Center, 2211 Emmons Avenue, Brooklyn, NY 11235, USA
Regardless of etiology, the pathogenesis of acute pancreatitis results in the extravasation of liters of intravascular fluid into the peritoneum. These losses manifest in the development of pancreatic ascites, hypotension, tachycardia, and further destruction of the pancreas, also referred to as "pancreatic necrosis." Impairment of the microcirculation of the pancreas appears to lead to pancreatic necrosis. A vicious cycle develops in which pancreatic inflammation leads to extravasation of protein-rich intravascular fluid into the peritoneum. The intravascular hypovolemia that accompanies acute pancreatitis subsequently leads to a decrease in pancreatic blood flow. Pancreatic ischemia leads to the activation of inflammatory mediators. The decreased blood flow also causes stasis and the development of thrombi, leading to subsequent necrosis, which then exacerbates the inflammatory process. The association of hemoconcentration, in which the hematocrit (HCT) level rises, with pancreatic necrosis

Fig 1. In acute pancreatitis, hypoperfusion to the pancreas results in increased pancreatic necrosis, which leads to the release of proinflammatory mediators, which in turn exacerbates hypoperfusion, leading to greater necrosis and a rise in hematocrit (HCT). illustrates this process (Fig. 1).

Vigorous intravenous hydration leads to hemodilution and relief of hemoconcentration. This translates into direct benefits for the patient with acute pancreatitis. A decreased hematocrit is associated with mild disease. Also, a falling hematocrit during the first $24 \mathrm{~h}$ of care leads to a decrease in morbidity. Clinical studies with aggressive plasma volume expansion using intravenous dextran to promote hemodilution have suggested efficacy in preventing severe disease. Although dextran is not used clinically at present, isotonic saline is our practical alternative. It appears that vigorous intravenous hydration early in the course of acute pancreatitis can prevent the development of necrosis.

The goal in managing patients with acute pancreatitis is to decrease the hematocrit, achieve hemodilution, decrease the blood urea nitrogen (BUN) and creatinine, and promote renal blood flow. By preventing intravascular depletion of fluid and promoting pancreatic blood flow, pancreatic perfusion is maintained. By maintaining pancreatic perfusion, pancreatic necrosis and the complications of pancreatitis leading to severe disease are prevented (Fig. 2).

Too often, patients with acute pancreatitis are given suboptimal intravenous hydration, resulting in pancreatic necrosis and organ failure. How much fluid should be given? Part of the answer is related to the amount of losses the patient presents with, and the other part is related to continuing losses due to the ongoing pancreatic inflammatory process. A patient who presents with hypotension and tachycardia clearly needs more aggressive hydration than one who is normotensive with a normal baseline pulse. Regardless of this, clinicians must suspect that a patient with acute pancreatitis will subsequently develop serious intravascular fluid losses. One of the markers of severity previously defined by Ranson and colleagues is related to intravascular losses. Ranson et al. (1976) found that sequestration (i.e., peritoneal pancreatic ascites) of over $6 \mathrm{~L}$ of fluid during the first $48 \mathrm{~h}$ was

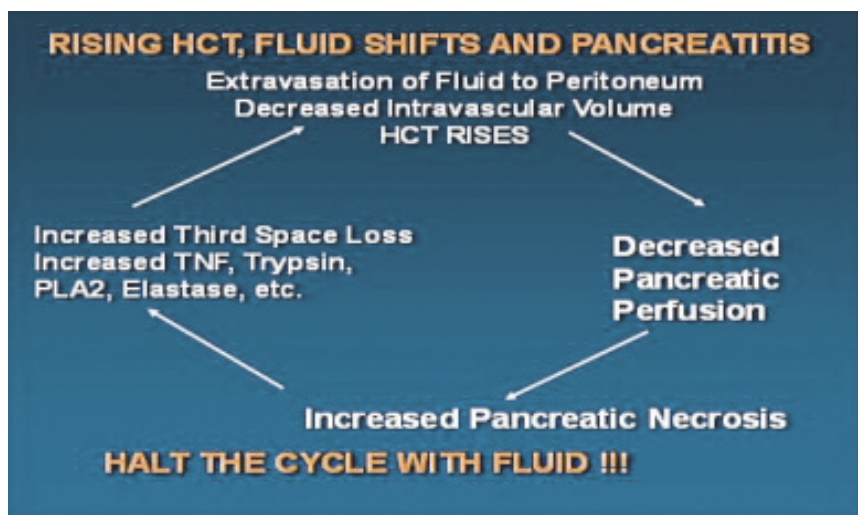




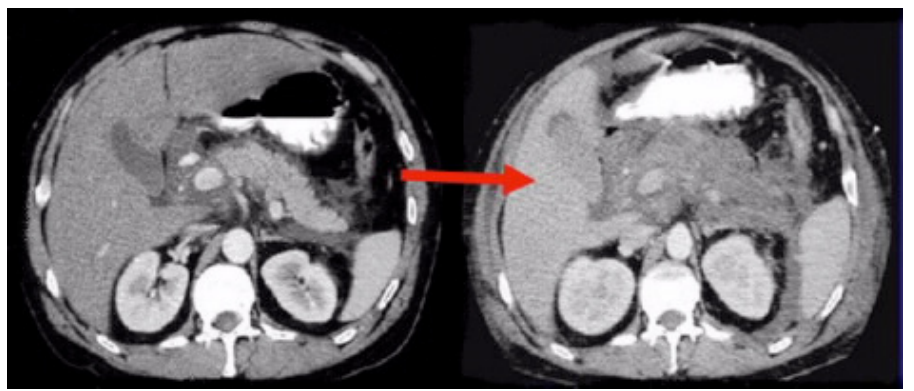

Fig 2. Progression to pancreatic necrosis. These images show the progression of pancreatic necrosis in a patient with acute pancreatitis. The dynamic CT scan performed on day 1 shows opacification of the kidneys, spleen, and pancreas. In contrast, a repeat CT scan on day 3 shows opacification of the kidneys and spleen, but no pancreatic opacification. These images demonstrate a loss of pancreatic perfusion between days 1 and 3 of the disease. This patient was poorly hydrated $(150 \mathrm{~mL} / \mathrm{h})$ and developed adult respiratory distress syndrome (ARDS), renal failure, and had a rise in HCT from $42 \%$ to $46 \%$.

an independent predictor of severity. A patient with mild disease routinely would lose 3-5 $\mathrm{L}$ into the peritoneum.

Not including baseline losses, how much intravenous hydration is needed? If we use the Ranson upper limit of severity of an amount of $6 \mathrm{~L}$ (expected losses), added to the minimal intravenous fluid requirements of a 70 $\mathrm{kg}$ person during the first $48 \mathrm{~h}(8 \mathrm{~L})$, intravenous hydration should be at least 300-350 mL per hour initially. The rate of hydration is likely to be more important during the first $24 \mathrm{~h}$, when a rising HCT has been shown to correlate closely with severe disease. The rate of hydration should be titrated to the hematocrit. The goal is to decrease the hematocrit $5-10$ points during the first $24 \mathrm{~h}$.

There are multiple caveats to the basic assumption of the initial rate of hydration. In a patient with acute pancreatitis, in order to guide hydration, the clinician must take into account the patient's age, underlying cardiac, renal and pulmonary disease, and body mass index (BMI). Whereas all elderly patients need to be followed closely, those with renal and cardiovascular disease may need intracardiac monitoring to guide hydration and prevent congestive heart failure. Over the last several years, we have learned that patients who are obese, with an elevated BMI, are at increased risk of pancreatic necrosis, organ failure, and death. It is likely that the reason why obese patients (those with an elevated $\mathrm{BMI}$ ) are more likely to have complicated disease is directly related to inadequate intravenous hydration When one considers that a $100-\mathrm{kg}$ male who is $1.93 \mathrm{~m}$ ( 6 feet 4 inches) tall needs a baseline of almost $400 \mathrm{~mL} /$ h of hydration, it becomes apparent that if the same patient develops acute pancreatitis, he is far more likely to receive inadequate hydration in comparison with a normal person.

Which type of fluid should be used? In order to promote perfusion and maintain intravascular pressure, the fluid should be isotonic. Hypertonic solutions, which would maintain or even increase intravascular pressure, are being studied but are considered experimental. The two widely available isotonic solutions are "normal" $(0.9 \%)$ saline and lactated Ringer's solution.

There are several theoretical benefits to using the more $\mathrm{pH}$-balanced lactated Ringer's solution for fluid resuscitation in comparison with normal saline. Although both are crystalloid solutions, the development of non-anion gap, hyperchloremic metabolic acidosis associated with the infusion of large volumes of normal saline has been well described. On the basis of the metabolic acidosis associated with largevolume infusion of normal saline and the available evidence suggesting that the inflammation associated with acute pancreatitis is a $\mathrm{pH}$-dependent process, resuscitation with lactated Ringer's solution may have significant benefits over normal saline in the early treatment of patients with acute pancreatitis.

\section{Summary}

In a patient who is otherwise healthy, presenting as normotensive with minimal tachycardia, intravenous hydration with lactated Ringer's solution at $250-350 \mathrm{~mL} / \mathrm{h}$, depending on BMI, should be initiated and maintained until the acute inflammatory process resolves. The goal is to decrease the hematocrit by at least three points from baseline (below 44\%). On the basis of animal studies, the goal may be to decrease the hematocrit to the mid- $30 \%$ range. If the patient presents as hypotensive and tachycardic, intravenous hydration should be much more aggressive-e.g., $500 \mathrm{~mL} /$ $\mathrm{h}$ minimum. Currently, there is no specific therapy available to attenuate the inflammatory response in acute pancreatitis. Instead, practice guidelines universally recommend supportive care with intravenous hydration.

\section{Further Reading}

Baillargeon JD, Orav J, Ramagopal

V, Tenner SM, Banks PA.

Hemoconcentration as an early risk factor for necrotizing pancreatitis. Am J Gastroenterol 1998;93:2130-4.

Gardner TB, Vege SS, Pearson RK, Chari ST. Fluid resuscitation in acute pancreatitis. Clin Gastroenterol Hepatol 2008;6:1070-6.

Klar E, Herfarth C, Messmer K. Therapeutic effect of isovolemic hemodilution with dextran 60 on the impairment of pancreatic microcirculation in acute biliary pancreatitis. Ann Surg 1990;211:346-53.

Ranson JH, Rifkind KM, Turner JW. Prognostic signs and nonoperative peritoneal lavage in acute pancreatitis. Surg Gynecol Obstet 1976;143:209-19.

Tenner S. Initial management of acute pancreatitis: critical decisions during the first 72 hours. Am J Gastroenterol 2004;99:2489-94. 


\section{Management of autoimmune pancreatitis: a review of medical therapy}

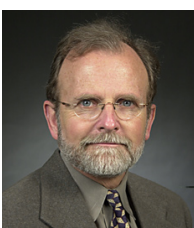

Ashraf Saleemuddin, MD and

William R. Brugge*, MD ("photo)

Tufts University School of Medicine and Massachusetts General Hospital, Boston, Massachusetts, USA

\section{Introduction}

The mainstay of medical therapy for autoimmune pancreatitis (AIP) is administration of oral corticosteroids. A variety of regimens have been described and used, but there is a lack of consensus regarding duration, dosing, and alternatives. Although corticosteroid therapy is highly effective, supplementary therapy is important in patients who have suffered from side effects or complications of corticosteroids. The role of immunosuppressive agents has recently been explored in a small number of patients. We have reviewed the available literature on the medical therapy of autoimmune pancreatitis and compared it to surgical therapy.

\section{Methods}

A text-word literature review was performed using the PubMed and Medline databases. Terms including "autoimmune pancreatitis," "treatment of autoimmune pancreatitis," and "management of autoimmune pancreatitis" were used for a comprehensive search over the past 20 years. Published manuscripts providing original reports of medical and surgical therapy of AIP in peer-reviewed journals were critically reviewed. Responses (clinical, radiologic, and serologic) to the regimens described were compiled in a table format. Nine manuscripts describing therapy for AIP in 101 patients were critically reviewed for the dose, duration of therapy, and alternatives to corticosteroid therapy. The surgical therapy was also reviewed and used as a comparison.

\section{Critical literature review}

Autoimmune pancreatitis (AIP)

is a form of chronic pancreatitis characterized by lymphoplasmacytic cellular infiltration of the pancreas, as well as other organs. The infiltration may involve the ducts, parenchyma, or both. Although AIP is characterized by clear clinical, histologic, radiologic, and serologic findings, differentiating the inflammatory process from pancreaticobiliary malignancies remains a challenge. Medical therapy for AIP consists primarily of short (1-2 months) or medium (2-6 months) courses of corticosteroids. The use of corticosteroids provides an opportunity for therapy as well as a diagnostic assessment in terms of resolution of pancreatic lesions.

In a recent series, the success of treatment with corticosteroids was defined as resolution of the histologic, radiologic, and serologic parameters [1]. In this series, a week's course of prednisone $30-40 \mathrm{mg} /$ day was followed by daily dose tapering of 2.5$5.0 \mathrm{mg} /$ week. All patients treated with steroid therapy for 1 month showed a significant reduction in the pancreatic abnormality as defined by the results of computed tomography (CT) and magnetic resonance imaging (MRI). In addition, serum gamma-globulin, IgG, and CA19-9 levels returned to normal during the course of the corticosteroid therapy. The patients were followed for a period of between 12 and 142 months and there were no indications for progression of pancreatic malignancy and no recurrence of symptoms of jaundice or abdominal pain. A poor response to 1-2 weeks of corticosteroid therapy should raise concern for the possibility of pancreatic cancer or forms of non-AIP chronic pancreatitis.

\section{Short-course corticosteroids}

Hirano et al. have described the response to a short course of steroids [2]. Nineteen patients diagnosed with AIP using the Mayo Clinic criteria were treated with a prednisone dose of 25-50 mg per day for 2-4 weeks. The dose was tapered by $5 \mathrm{mg}$ every 2-4 weeks until the daily dose reached $5 \mathrm{mg}$, followed by maintenance therapy at a dose of $2.5-5.0 \mathrm{mg} /$ day. In all 19 patients, imaging findings and laboratory abnormalities improved 4 weeks after initiation of steroid therapy. In comparing AIP patients treated with corticosteroids and to those patients not treated, it was found that AIP-related unfavorable events such as jaundice, abnormal liver function tests, and pancreatic pseudocyst were reduced in the corticosteroid-treated group. During follow-up of the patients not treated with corticosteroids, it was found that unfavorable events were observed in 16 of 23 patients $(70 \%)$ after 25 months on average from onset.

The effectiveness of corticosteroid therapy may be due to its role in improving bile duct stenosis in patients with obstructive jaundice. Using a longer course of corticosteroids, Ito 
Table 1. Response of patients with autoimmune pancreatitis (AIP) to steroid therapy. All studies included in the table are sources of primary data.

\begin{tabular}{|c|c|c|c|c|c|}
\hline First author, ref. & $\begin{array}{l}\text { Patients } \\
\text { (n) }\end{array}$ & Diagnostic criteria & Dose & Steroid therapy duration & $\begin{array}{l}\text { Responses to } \\
\text { therapy (n) }\end{array}$ \\
\hline Song [1] & 4 & $\begin{array}{l}\text { 1, diagnostic histopathologic features and bound lgG4+ } \\
\text { plasma cells on pancreatic tissues; } 2 \text {, characteristic imaging } \\
\text { on } \mathrm{CT} \text { and pancreatography, together with increased serum } \\
\text { IgG, gamma-globulin levels or presence of autoantibodies; } 3 \text {, } \\
\text { response to steroid therapy }\end{array}$ & $\begin{array}{l}30-40 \mathrm{mg} / \mathrm{d} \times \\
1 \mathrm{wk}\end{array}$ & Taper daily dose by $2.5-5 \mathrm{mg} / \mathrm{wk}$ & 4 \\
\hline $\begin{array}{l}\text { Hirano [2], } \\
\text { Nishimori [16] }\end{array}$ & 19 & Mayo * & $\begin{array}{l}25-50 \mathrm{mg} / \mathrm{d} \times \\
2-4 \mathrm{wk}\end{array}$ & $\begin{array}{l}\text { Taper } 5 \mathrm{mg} \text { every } 2-4 \mathrm{wk} \text { until } \\
5 \mathrm{mg} / \mathrm{d} \text {, then } 2.5-5.0 \mathrm{mg} / \mathrm{d} \text { for } \\
\text { maintenance }\end{array}$ & 19 \\
\hline Ito [8] & 14 & JPS $\dagger$ & $\begin{array}{l}30,40 \mathrm{mg} / \mathrm{d} \times \\
2 \mathrm{wk}\end{array}$ & Taper over 2-3 months & $\begin{array}{l}98.4 \% \text { remis- } \\
\text { sion rate }\end{array}$ \\
\hline Kamisawa [7] & 10 & $\begin{array}{l}\text { Enlargement of the pancreas, irregular narrowing of the } \\
\text { MPD, } \neq \text { hypergammaglobulinemia (over } 2.0 \mathrm{~g} / \mathrm{dL}) \text {, elevated } \\
\text { serum (IgG4, over } 135 \mathrm{mg} / \mathrm{dL}) \text {, presence of autoantibod- } \\
\text { ies, and lymphoplasmacytic infiltration with fibrosis of the } \\
\text { pancreas }\end{array}$ & $30-40 \mathrm{mg} / \mathrm{d}$ & Taper by $5 \mathrm{mg}$ every $1-2 \mathrm{wk}$ & 10 \\
\hline Okazaki [17] & 21 & JPS & $\mathrm{NI} \S$ & $\mathrm{Nl}$ & $\mathrm{Nl}$ \\
\hline Kubota [4] & 12 & JPS & $30 \mathrm{mg} / \mathrm{d} \times 2 \mathrm{wk}$ & $\begin{array}{l}\text { Taper by } 5 \mathrm{mg} / \mathrm{wk} \text { until daily } \\
\text { does of } 5 \mathrm{mg} \text { reached }\end{array}$ & 12 \\
\hline Church [6] & 11 & $\begin{array}{l}\text { 1, increased levels of serum gammaglobulin or lgG4; } 2 \text {, } \\
\text { presence of autoantibodies; } 3 \text {, diffuse enlargement of the } \\
\text { pancreas or a pancreatic mass; } 4 \text {, diffuse irregular narrowing } \\
\text { of the MPD; } 5 \text {, fibrotic changes with lymphocyte infiltration; } 6 \text {, } \\
\text { no symptoms or only mild symptoms, usually without attacks } \\
\text { of acute pancreatitis; } 7 \text {, rare pancreatic calcification or cysts; } \\
8, \text { occasional association with other autoimmune diseases; } \\
9 \text {, effective steroid therapy }\end{array}$ & $30 \mathrm{mg} / \mathrm{d}$ & Tapered over 2-3 months & 11 \\
\hline Kamisawa [18] & 10 & $\begin{array}{l}\text { Swelling of the pancreas, irregular narrowing of the MPD, } \\
\text { hypergammaglobulinemia, elevation of serum IgG4, pres- } \\
\text { ence of autoantibodies, association with other autoimmune } \\
\text { diseases, and lymphoplasmacytic infiltration with fibrosis }\end{array}$ & $5,30,40,60 \mathrm{mg} / \mathrm{d}$ & $\begin{array}{l}\text { Tapered by } 2.5-5 \mathrm{mg} \text { every } \\
1-2 \mathrm{wk}\end{array}$ & 10 \\
\hline Ito [3] & 3 & $\begin{array}{l}\text { Hypergammaglobulinemia, eosinophilia, US showing hy- } \\
\text { poechoic diffuse swelling of pancreas, ERCP showing diffuse } \\
\text { narrowing of the MPD with irregular thumbprint-like marks, } \\
\text { reversible exocrine insufficiency, and positive anticarbonic } \\
\text { anhydrase II antibody }\end{array}$ & $30 \mathrm{mg} / \mathrm{d}$ & 1 month & 3 \\
\hline Chari [9] & 17 & Mayo & $40 \mathrm{mg} / \mathrm{d} \times 4 \mathrm{wk}$ & Tapered by $5 \mathrm{mg} /$ wk over 8 wk & 17 \\
\hline Moon [10] & 22 & $\begin{array}{l}\text { Previously reported "cardinal features of AIP" and one of } \\
\text { following imaging features: } 1 \text {, diffuse pancreatic enlargement } \\
\text { with or without capsule-like rim; } 2 \text {, delayed enhancement of } \\
\text { pancreatic mass; } 3 \text {, diffusely attenuated MPD with irregular } \\
\text { wall; } 4 \text {, none-to-mild upstream duct dilation despite long } \\
\text { stricture; } 5 \text {, double duct sign without a pancreatic mass in } \\
\text { a patient with obstructive jaundice; } 6 \text {, association of hilar or } \\
\text { intrahepatic duct strictures; or } 7 \text {, other organ involvement } \\
\text { unusual for pancreatic cancer such as a salivary gland, } \\
\text { kidney, or retroperitoneal fibrosis }\end{array}$ & $\begin{array}{l}0.5 \mathrm{mg} / \mathrm{kg} / \mathrm{d} \times \\
1-2 \text { months }\end{array}$ & $\begin{array}{l}\text { Tapered by } 5-10 \mathrm{mg} / \mathrm{month} \text { to } \\
\text { dose of } 2.5-7.5 \mathrm{mg} / \mathrm{d}\end{array}$ & 15 \\
\hline Ghazale [11] & 30 & Mayo & $40 \mathrm{mg} / \mathrm{d} \times 4 \mathrm{wk}$ & $\begin{array}{l}\text { Tapered by } 5 \mathrm{mg} / \mathrm{wk} \text { for total } \\
\text { of } 11 \mathrm{wk}\end{array}$ & 29 \\
\hline
\end{tabular}

* Mayo criteria: Histology: 1, periductal lymphoplasmacytic infiltrate with obliterative phlebitis and storiform fibrosis or 2, lymphoplasmacytic infiltrate with storiform fibrosis showing abundant (> 10 cells/high-powered field) IgG4-positive cells; Typical: diffusely enlarged gland with delayed (rim) enhancement; diffusely irregular, attenuated main pancreatic duct; Other: focal pancreatic mass/enlargement; focal pancreatic duct stricture; pancreatic atrophy; pancreatic calcification; or pancreatitis; elevated serum lgG4 level (normal, 8-140 mg/dL); hilarl intrahepatic biliary strictures, persistent distal biliary strictures, persistent distal biliary stricture, parotid/lacrimal gland involvement, mediastinal lymphadenopathy, retroperitoneal fibrosis; resolution/marked improvement of pancreatic/extrapancreatic manifestation with steroid therapy.

$\dagger$ Japan Pancreas Society criteria: Typical imaging: diffuse enlargement of pancreas along with diffuse (>33\%) main pancreatic duct narrowing with an irregular wall and 1, serology: autoantibodies, elevated gamma-globulins or lgG or 2, histopathology: Iymphoplasmacytic infiltrate and pancreatic fibrosis.

$\ddagger$ Main pancreatic duct.

$\S$ Not indicated in paper. 
et al. described the course of 125 patients diagnosed with AIP as defined by the Japanese Pancreas Society (JPS) criteria [3]. The patients were started on a prednisone dose of $30 \mathrm{mg}$ or $40 \mathrm{mg}$ for 2 weeks and tapered over $2-3$ months, leading to a $98.4 \%$ remission rate (123 of 125). The authors found that patients who had corticosteroid therapy took 89.7 days on average to reach complete remission, whereas those patients without corticosteroid therapy took 149.8 days to reach complete remission. It is important to note that untreated patients demonstrated a high rate of spontaneous remission.

With increasing experience with the initial corticosteroid therapy, it has become apparent that short courses might be as effective as a moderate course of corticosteroids. In the series by Kubota et al., 12 patients were diagnosed with AIP using the JPS criteria and started on $30 \mathrm{mg} /$ day for 2 weeks [4]. The dose was tapered by $5 \mathrm{mg}$ per week until a daily dose of $5 \mathrm{mg}$ was reached. All 12 patients showed a complete response to steroid therapy.

The pace of corticosteroid tapering in the initial therapy of AIP has been described by Kamisawa et al. [5]. Ten patients were diagnosed with AIP using the following criteria: enlargement of the pancreas, irregular narrowing of the main pancreatic duct (MPD), hypergammaglobulinemia (over $2 \mathrm{~g} /$ $\mathrm{dL}$ ), presence of autoantibodies, and lymphoplasmacytic infiltration with fibrosis of the pancreas. All 10 patients were started on 30-40 mg/day of prednisone, and the dose was tapered by $5 \mathrm{mg}$ every $1-2$ weeks. Steroid therapy was effective morphologically and serologically in all 10 patients with AIP. Pancreatic enlargement showed improvement from 1 to 2 weeks after initiation of treatment, and the pancreas returned to normal size within 34 weeks after the start of therapy.

\section{Symptom response to corticosteroids}

The symptoms of AIP, including jaundice will also resolve with corticosteroid therapy [6]. Eleven patients were started on a corticosteroid dose of $30 \mathrm{mg}$ per day, which was tapered over 2-3 months, and in all patients there was an improvement of symptoms within 4 weeks. Jaundice and abdominal pain were eliminated over the course of treatment.
Improvement in serologic values also improved with the symptoms.

A number of radiologic and serologic criteria can be used to monitor response to therapy. Kamisawa et al. tracked the serologic, morphologic, and imaging response to corticosteroids [7]. Ten patients diagnosed with the criteria indicated in Table 1 were started on initial prednisone doses of $5,30,40$, or $6 \mathrm{mg}$ per day. The doses were tapered by $2.5-5.0 \mathrm{mg}$ every $1-2$ weeks, and all 10 patients improved clinically as well as with objective criteria. In a small series of patients, Ito et al. have demonstrated the response to prednisone $30 \mathrm{mg} /$ day [8]. Three patients were treated with $30 \mathrm{mg} /$ day for 1 month, and all responded to treatment as defined by clinical symptoms and radiologic changes. Since the pancreas can sometimes undergo marked atrophy after corticosteroid therapy, the authors suggest that steroids should be discontinued after adequate morphological improvement.

The pancreatic manifestations of AIP should be responsive to corticosteroid therapy. In the study by Chari et al., 17 AIP patients were followed for a period of between 2 and 56 months, and all patients showed complete resolution of pancreatic manifestations
Table 2. Response of patients with autoimmune pancreatitis (AIP) treated with surgical resection.

\begin{tabular}{|c|c|c|c|c|}
\hline $\begin{array}{l}\text { First author, } \\
\text { ref. }\end{array}$ & Patients (n) & Type of surgical resection & $\mathrm{n}$ & Response to therapy ( $n$ ) \\
\hline \multirow[t]{4}{*}{ Song [1] } & \multirow[t]{4}{*}{$21 / 43$} & Pancreaticoduodenectomy & 4 & \multirow{4}{*}{$\begin{array}{l}\text { All resections done in } \\
\text { this study for suspected } \\
\text { pancreatic malignancy }\end{array}$} \\
\hline & & Choledochojejunostomy & 14 & \\
\hline & & $\begin{array}{l}\text { Radiofrequency ablation of pancreatic } \\
\text { head }\end{array}$ & 1 & \\
\hline & & $\begin{array}{l}\text { Intraoperative biopsy of pancreatic tis- } \\
\text { sues }\end{array}$ & 2 & \\
\hline Ito [3] & $2 / 21$ & Pancreatic resection & 2 & \\
\hline \multirow[t]{2}{*}{ Toomey [12] } & \multirow[t]{2}{*}{2} & $\begin{array}{l}\text { Diagnostic laparoscopy with choledocho- } \\
\text { jejunostomy }\end{array}$ & 1 & 1 \\
\hline & & $\begin{array}{l}\text { Diagnostic laparoscopy with biopsies and } \\
\text { subsequent steroid therapy }\end{array}$ & 1 & 1 \\
\hline \multirow[t]{2}{*}{ Kamisawa [7] } & \multirow[t]{2}{*}{10} & Pancreatoduodenectomy & 6 & 6 \\
\hline & & Choledochojejunostomy & 4 & 4 \\
\hline Hardacre [13] & 37 & Pancreaticoduodenectomy & 37 & $\begin{array}{l}68 \% \text { improved (subjec- } \\
\text { tive) }\end{array}$ \\
\hline \multirow[t]{3}{*}{ Weber [14] } & \multirow[t]{3}{*}{29} & Pancreaticoduodenectomy & 23 & \multirow{3}{*}{$\begin{array}{l}8 / 29 \text { developed recur- } \\
\text { rence of symptoms }\end{array}$} \\
\hline & & Distal pancreatectomy & 4 & \\
\hline & & Total pancreatectomy & 2 & \\
\hline
\end{tabular}




\begin{tabular}{|l|l|l|l|}
\hline First author, ref. & $\mathrm{n}$ & Alternative medical therapy & Response to therapy $(\mathrm{n})$ \\
\hline Church [6] & 6 & Azathioprine $1-2 \mathrm{mg} / \mathrm{kg} / \mathrm{d}$ & 4 \\
\hline Topazian [15] & 1 & $\begin{array}{l}\text { Rituximab } 375 \mathrm{mg} / \mathrm{m} 2 \text { weekly for } \\
\text { four doses }\end{array}$ & 1 \\
\hline
\end{tabular}

Table 3. Response of patients with autoimmune pancreatitis (AIP) patients treated with alternative medical therapy

[9]. The authors also demonstrated that bile duct strictures are responsive to corticosteroid therapy. Of the 17 patients, three had intrahepatic biliary strictures and five had obstructive jaundice with distal biliary strictures. All eight of these patients showed marked improvement and resolution of biliary manifestations, with a normal biliary tree and pancreatic duct on follow-up imaging.

\section{Diagnostic course of steroids}

A course of corticosteroids is used primarily to provide therapy, but corticosteroids can also be used diagnostically. Moon et al. showed that in 22 patients diagnosed with AIP using a blend of criteria, 15 responded to steroids, whereas the seven patients who did not respond were found to have pancreatic cancer [10]. All 22 patients were treated with an initial dose of prednisone $(0.5 \mathrm{mg} / \mathrm{kg} /$ day $)$ for 2 weeks. A positive response to steroids was defined by complete resolution or significant improvement of MPD narrowing and resolution, or a significant reduction of the pancreatic mass. A negative response to corticosteroids was defined as a lack of improvement of MPD narrowing and no resolution or reduction of the pancreatic mass. In the 15 patients who responded favorably to corticosteroids, there was complete resolution, as demonstrated by symptomatic, radiologic, and serologic improvement. This remission was achieved with a regimen of prednisone $0.5 \mathrm{mg} / \mathrm{kg} /$ day for 1-2 months, followed by a gradual taper of 5-10 mg/month to a maintenance dose of $2.5-7.5 \mathrm{mg} / \mathrm{day}$, which was continued for an average of 6 months. In the other group, those who had a "negative steroid response," all seven patients showed narrowing of the MPD and enlargement of the pancreas with disease progression. The study by Moon et al. clearly shows the value of a short-duration trial of steroid therapy in assessing for steroid responsiveness in suspected AIP patients. The 2-week duration of steroids used in this trial did not appear to have a negative impact on those patients with pancreatic malignancy. It is important to note that this diagnostic trial should be reserved for patients who have had an extensive evaluation for the possibility of malignancy, including a pancreatic biopsy or aspiration cytology.

Finally, Ghazale et al. investigated the response of strictures to corticosteroid therapy [11]. In this series of 30 patients diagnosed with AIP using the Mayo criteria, the patients were treated with $40 \mathrm{mg} /$ day prednisone for 4 weeks. The dose was tapered by $5 \mathrm{mg}$ per week for a total of 11 weeks of treatment. Twenty-nine of the 30 patients responded to corticosteroids. One patient remained refractory to steroids and required prolonged biliary stenting. Liver enzyme levels normalized in $61 \%$ of the 30 patients.

\section{Surgical management of AIP}

Autoimmune pancreatitis (AIP) can be very difficult to distinguish from a focal malignancy such as pancreatic adenocarcinoma, as the clinical presentation and radiologic findings can be very similar. The lingering suspicion of an occult malignancy often stimulates clinicians to pursue further diagnostic testing. Although a careful evaluation before and after steroid therapy provides additional evidence of a malignant or a benign process, surgical therapy and a pancreatic resection are at times indicated.

In a series of 43 patients with a presumptive diagnosis of AIP, Song et al. found that a significant percentage of patients required a diagnostic surgical exploration [1]. Twentyone of the 43 patients diagnosed with AIP underwent exploratory laparotomy due to the possibility of a misdiagnosed pancreaticobiliary malignancy. Unfortunately, pancreatic biopsy or fine-needle aspiration (FNA) may provide false-negative results in terms of malignancy. Clinical manifestations and radiologic, histologic, and serologic evidence are therefore used to detect clues for a diagnosis of an occult pancreatic malignancy. Toomey et al. described two cases of AIP in which one patient underwent a diagnostic laparoscopy with choledochojejunostomy and the other underwent a diagnostic laparoscopy with intraoperative biopsies and subsequent steroid therapy [12]. The indications for surgical exploration were met after failure to satisfy all diagnostic criteria, coupled with a suspicion of malignancy. Both patients did well postoperatively and did not have a relapse of their AIP. Kamisawa et al. followed six patients who underwent pancreatoduodenectomy and four patients who underwent choledochoduodenostomy [7]. All patients in both groups showed improvement of their jaundice. One patient in the pancreatoduodenectomy group progressed to Sjögren syndrome, with swelling of the cervical lymph nodes, and underwent corticosteroid therapy. Another patient in the choledochoduodenostomy group developed hydronephrosis, probably due to associated retroperitoneal fibrosis, and subsequently underwent steroid therapy.

The surgical approach to AIP includes resection for diagnostic considerations as well as for therapy. In a study by Hardacre et al., 37 patients 
with AIP (termed "lymphoplasmacytic sclerosing pancreatitis," LPSP) underwent pancreaticoduodenectomy for suspicion of malignant disease [13]. Postoperatively, none of the patients was noted to have recurrent jaundice. One patient in the group suffered from recurrent episodes of acute pancreatitis, manifested by abdominal pain and elevated serum amylase and lipase levels. In a study by Weber et al., 29 patients diagnosed with AIP (referred to as LPSP) were found to be candidates for curative resection of the pancreas. Of the 29 patients, almost one-third (eight of 29) developed a recurrence of symptoms, with seven showing jaundice and one with recurrent pancreatitis [14]. It is important to note that the seven patients with recurrent jaundice were found to have biliary stricturing at the time of direct cholangiography. All 29 patients were confirmed as having AIP by pathologic classification, and there were no signs of malignancy.

\section{Noncorticosteroid therapy}

Comparisons of maintenance corticosteroid treatment with the use of immunomodulatory drugs have not been well investigated. Cases have been reported sporadically, with varying responses to treatment. It is important to realize that as with lowdose steroids, immunomodulatory drugs such as azathioprine and mycophenolate mofetil have their own side effects. Church et al. described a series of 11 patients diagnosed with AIP who were treated with prednisolone therapy over a 2-3-month period [6]. During an 18-month follow-up, six of the 11 patients relapsed on reduction of the steroid dose, at which point the prednisolone dose was increased and azathioprine 1-2 $\mathrm{mg} / \mathrm{kg} /$ day was initiated. Four of the six patients (one patient declined azathioprine) improved on the combined steroid and azathioprine treatment. Ghazale et al. also reported that recurrence of disease-related symptoms was associated with biochemical and/ or serologic relapse in 16 of 30 corticosteroid-treated AIP patients
(53\%) [11]. Six of the 16 patients were treated with either azathioprine (initially $50 \mathrm{mg} /$ day, increased $2.0-2.5 \mathrm{mg} /$ $\mathrm{kg}$ ), mycophenolate mofetil (500 mg twice daily, increased to $750 \mathrm{mg}$ twice daily) or cyclophosphamide (Cytoxan). The six patients were subsequently maintained in remission on these medications, without any further relapses after a median follow-up period of 6 months.

Topazian et al. recently documented the use of new immunomodulatory agent in a case report in which medical therapy with the monoclonal antibody rituximab produced a promising response [15]. The patient in this case report had immunoglobulin G-associated cholangitis (IAC), an entity with many features in common with AIP. The patient was treated with an 8-week tapering course of oral prednisone, starting with $50 \mathrm{mg} /$ day. The patient had recurrent abdominal pain and was re-treated with a 12week course of prednisone. His course was complicated by recurrent biliary strictures requiring biliary stenting and another course of corticosteroids. The biliary strictures persisted, and the patient received another 12week course of prednisone along with 6-mercaptopurine at a dose of $1.5 \mathrm{mg} / \mathrm{kg} /$ day for 8 months. After cholangiography and endosonography of the pancreas, a diagnosis of AIP and IAC with ocular involvement refractory to prednisone and 6-mercaptopurine was made. Therapy with rituximab at $375 \mathrm{mg} / \mathrm{m}^{2}$ weekly for four doses was initiated, primarily for therapy of the ocular disease. After 1 month of therapy, the patient began to notice improvement in his vision, his symptoms of jaundice and steatorrhea were relieved, and maintenance rituximab 375 mg/m² (every 3 months) was started. Four months after rituximab was initiated, endoscopic retrograde cholangiopancreatography (ERCP) showed improvement in the biliary strictures and allowed for removal of the biliary stents. The efficacy of rituximab has been documented in inflammatory diseases

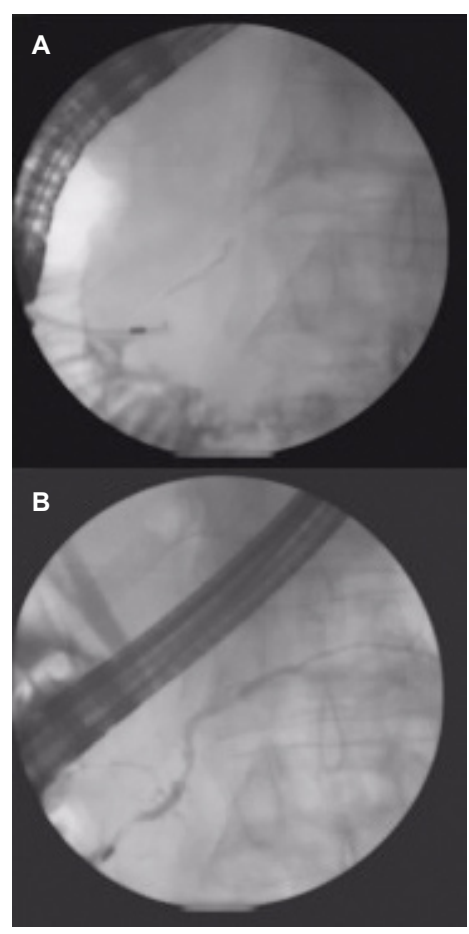

Fig 1. Endoscopic retrograde pancreatography (ERP) before (a) and after (b) 1 month of moderatedose corticosteroids.

such as rheumatoid arthritis. However, data with regard to duration and maintenance therapy have not been reported. Although the report by Topazian et al. [15] involved only one patient, the dramatic response to therapy has raised the possibility of rituximab providing an alternative to Imuran and 6-mercaptopurine.

\section{Summary}

The radiologic, clinical, and serologic findings associated with AIP are highly responsive to medical therapy. The vast majority of patients respond to a 1-month course of moderate doses of corticosteroids followed by low-dose corticosteroid therapy. Alternatives to corticosteroid therapy include immunosuppressants such as azathioprine. Patients not responding appropriately to medical therapy should be considered for surgical confirmation of AIP. 


\section{References}

1. Song Y, Liu QD, Zhou NX, et al. Diagnosis and management of autoimmune pancreatitis: experience from China. World J Gastroenterol 2008;14:601-6.

2. Hirano K, Tada M, Isayama H, et al. Longterm prognosis of autoimmune pancreatitis with and without corticosteroid treatment. Gut 2007;56:1719-24.

3. Ito $\mathrm{T}$, Nishimori I, Inoue N, et al. Treatment for autoimmune pancreatitis: consensus on the treatment for patients with autoimmune pancreatitis in Japan. J Gastroenterol 2007;42(Suppl 18):50-8.

4. Kubota K, lida H, Fujisawa T, et al. Clinical factors predictive of spontaneous remission or relapse in cases of autoimmune pancreatitis. Gastrointest Endosc 2007;66:1142-51.

5. Kamisawa T, Egawa N, Nakajima $\mathrm{H}$, et al. Morphological changes after steroid therapy in autoimmune pancreatitis. Scand J Gastroenterol 2004;39:115--8.

6. Church NI, Pereira SP, Deheragoda MG, et al. Autoimmune pancreatitis: clinical and radiological features and objective response to steroid therapy in a UK series. Am J Gastroenterol 2007;102:2417-25.

7. Kamisawa T, Yoshiike M, Egawa N, et al. Treating patients with autoimmune pancreatitis: results from a long-term followup study. Pancreatology 2005;5:234-40.
8. Ito T, Nakano I, Koyanagi S, et al.

Autoimmune pancreatitis as a new clinical entity. Three cases of autoimmune pancreatitis with effective steroid therapy. Dig Dis Sci 1997;42:1458-68.

9. Chari ST, Smyrk TC, Levy MJ, et al.

Diagnosis of autoimmune pancreatitis: the Mayo Clinic experience. Clin Gastroenterol Hepatol 2006;4:1010-6.

10. Moon SH, Kim MH, Park DH, et al. Is a two-week steroid trial after initial negative workup for malignancy useful in differentiating autoimmune pancreatitis from pancreatic cancer?: A prospective outcome study. Gut 2008;57:1704-12.

11. Ghazale A, Chari ST, Zhang L, et al. Immunoglobulin g4-associated cholangitis: clinical profile and response to therapy. Gastroenterol 2008;134:706-15.

12. Toomey DP, Swan N, Torreggiani W, et al. Autoimmune pancreatitis: medical and surgical management. JOP 2007;8:335-43.

13. Hardacre JM, lacobuzioDonahue CA, Sohn TA, et al. Results of pancreaticoduodenectomy for lymphoplasmacytic sclerosing pancreatitis. Ann Surg 2003;237:853-9.
14. Weber SM, Cubukcu-Dimopulo O, Palesty JA, et al. Lymphoplasmacytic sclerosing pancreatitis: inflammatory mimic of pancreatic carcinoma. J Gastrointest Surg 2003;7:129-9.

15. Topazian M, Witzig TE, Smyrk TC, et al. Rituximab therapy for refractory biliary strictures in immunoglobulin 64-associated cholangitis. Clin Gastroenterol Hepatol 2008:6:364-6.

16. Nishimori I, Tamakoshi A, Kawa S, et al. Influence of steroid therapy on the course of diabetes mellitus in patients with autoimmune pancreatitis: findings from a nationwide survey in Japan. Pancreas 2006;32:244-8.

17. Okazaki K. Autoimmune pancreatitis: etiology, pathogenesis, clinical findings and treatment. The Japanese experience. JOP 2005;6:89-96.

18. Kamisawa T, Egawa N, Inokuma S, et al. Pancreatic endocrine and exocrine function and salivary gland function in autoimmune pancreatitis before and after steroid therapy. Pancreas 2003;27:235-8. 


\section{TTT Trial Design Workshop Duraingens}

\section{1-2 April 2009 (Dubrovnik, Croatia)}

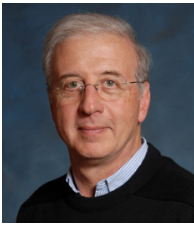

Jim Toouli, MD

WGO Coordinator for Education and Training Professor of Surgery, Flinders University, Adelaide, Australia
Topics at the TTT Trial Design Workshop

- Asking the question

- Logistics-planning a study

- Ethics and the institutional review board

- Choosing the best trial design

- Data collection, interpretation, statistics, analysis

- Successful grant writing
The first Trial Design Workshop was held in Dubrovnik in Croatia on 1-2 April. A survey of alumni at previous TTT courses had suggested that participants would welcome an extension of the "Trial Design" module. Professor Stimac of the Croatian Gastroenterology Society, a TTT faculty member, took up the challenge in conjunction with the TTT Committee, and a 2-day workshop with a small number of participants was planned.

Twenty-two people enrolled, representing eleven different countries. A faculty of seven from six different countries made up the rest of the group. The workshop was run with the now-familiar TTT format of lectures followed by small-group work and discussions conducted by the participants. In addition to the main topics covered (see box), the WGO Research Committee provided extensive references and materials for researchers to use in preparing and conducting their own clinical research.

As is the tradition at TTT meetings, social activities were included alongside the course. It's during these activities that friendships are made and potential future collaborations in research and other gastroenterologyrelated activities develop.

In general, evaluations of the course both by participants and by faculty members showed it had been a very successful new venture for WGO and effective in what it tried to achieve. Of course, only the future will show whether the event will lead to successful research by the members of the group. As coordinator of the workshop, I am particularly grateful to the dedicated faculty members for all the work that was done both before and during the meeting. I am also grateful to our Croatian hosts, who had the vision to see the importance of this type of event in enhancing our specialty. Finally, without the support of Medconnect and Tatjiana Jurcic and her colleagues, the course would not have been possible.

We in WGO look forward to repeating the Trial Design Workshop in other parts of the world and in conjunction with other national societies. This type of workshop would work well in conjunction with a major national society meeting, and we believe it could help enhance the quality of the overall meeting by providing a focused experience in a particular subject. Other topics that have been highlighted by TTT alumni as possible topics for future workshops include procedural skills training, assessment, and appraisal and credentialing.

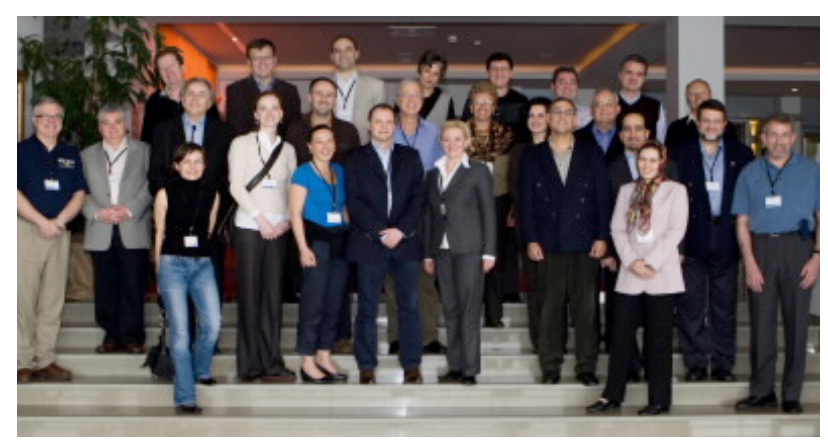

Participants and faculty gathered in the foyer of the Palace Hotel, Dubrovnik (the venue for the workshop). 


\section{WGO and ACG Global Collaboration Agreement}

The World Gastroenterology Organisation (WGO) and the American College of Gastroenterology (ACG) have agreed to a joint collaboration in which the organizations agreed to work in concert on a variety of key educational initiatives both in the U.S. and around the world. The goal of this partnership is to build upon the unique strengths and capacities of each organization to create synergies that promise to expand and enhance education for gastroenterologists worldwide. The initial agreement, which will last for a period of 5 years, covers a number of important educational programs, while opening the door to further collaboration on multiple fronts.

WGO's global reach and expertise combined with ACG's leading voice in clinical gastroenterology make this partnership a wonderful opportunity to expand and improve clinical gastroenterology practice and training around the world.

\section{Train the Trainers}

ACG shares WGO's commitment to and its approach to providing clinician educators with the skills needed to teach adult learners effectively. During the past several years, the ACG has become a frequent participant in TTT meetings across the world by sponsoring attendees. After participating in a number of ACG leaders have taken on the role of TTT faculty at subsequent meetings. The reports from the meetings have been uniformly outstanding, showing TTT to be a unique and important training opportunity for those teaching the future leaders and practitioners in clinical gastroenterology. ACG pursued these interests even further by hosting a TTT program in southern Florida in September of 2008; this was an outstanding success. It was after acting as a host society itself that the ACG gained a true appreciation for this onethe "Train the Trainers" (TTT) program programs as attendees, a number of of-a-kind international training program.

The impact these programs have on clinical gastroenterology across the globe is deeply appreciated by the ACG. As a result, ACG wanted to explore ways of supporting future TTTs. During the term of the agreement, ACG will therefore provide annual financial support for the Trainthe-Trainers programs as well as support for ACG faculty and attendees. The ACG will be recognized as a major sponsor of TTT with the WGO and will be recognized at each event as well as in promotional activities.

In addition to sponsoring future TTT meetings, the ACG will also have the ability to tap into the outstanding teaching and evaluation materials that have been developed for the program. It is the hope of both organizations that these materials can be expanded and applied to various types of programming in the U.S. that meet the specific and unique needs of the U.S. health care in training modules. An additional area of exploration includes developing a TTT style program appropriate for regular use with academic clinicians in the U.S. The WGO will obtain access to the data from any ACG-sponsored programming in the U.S., using the TTT or related materials for outcomes studies that may be produced.

\section{World Digestive Health Day Partners}

Another area of collaboration is in the annual World Digestive Health Day. The ACG will partner with the WGO to develop education and awareness programs in the United States based on the topics selected by the WGO. These activities will begin this year with the topic of irritable bowel syndrome (IBS) and will continue in future years as well. Through joint efforts involving media and strategic communications, both groups will maximize their potential to deliver important health messages to patients on IBS and digestive health generally will be maximized.

\section{International Training Centers}

Through this collaboration agreement, the ACG and WGO have also pledged to explore opportunities to work together in support of the WGO's initiative to develop and support training centers around the world. Among the possible areas for collaboration are sponsoring trainee scholarships to support travel to the centers; supporting educational programs at the centers; providing faculty and teaching materials to the centers; and assisting with networking opportunities amongst the existing centers.

The ACG and WGO very much look forward to this new phase in their long-standing partnership and expect that the benefits of working together on issues critical to the future advancement of clinical gastroenterology and improving patient outcomes will flow across the United States and the entire world. The ACG recognizes the important contribution made by Dr. Eamonn Quigley to the cultivation of this opportunity to partner with WGO. As current President of the College, and in light of his role in WGO, Dr. Quigley is well-positioned to see the tremendous potential for successful collaboration from the points of view of both organizations and also to represent their mutual interests.

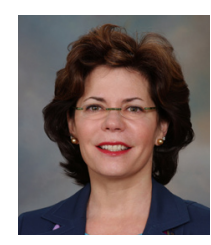

\section{Amy Foxx-Orenstein, MD}

Immediate Past President, American College of Gastroenterology Division of Gastroenterology and Hepatology, Department of Internal Medicine, Mayo Clinic, 200 First Street SW, Rochester, MN 55905, USA. 


\section{Endoscopy workshop in Ghana}

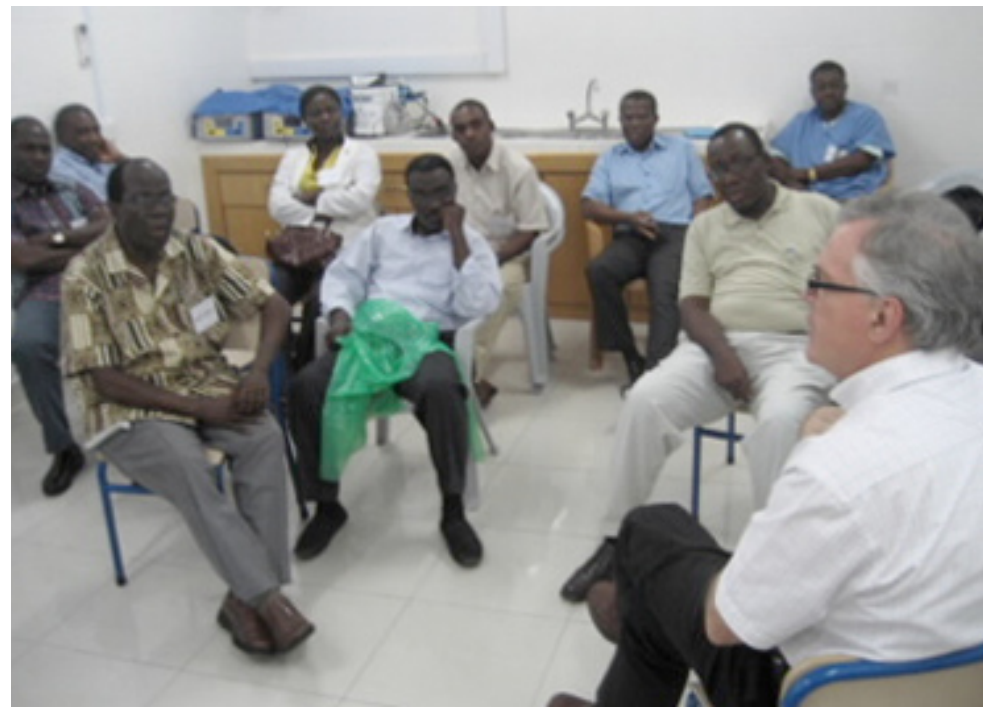

Dr. Quigley leads a lunchtime discussion.

The WGO co-sponsored a gastrointestinal endoscopy workshop at the Korle Bu Teaching Hospital in Accra, Ghana, from 29 September to 2 October 2008. The workshop, which was also sponsored by the Mayo Clinic and by the Korle Bu Medical Center, was designed to provide instruction in colonoscopy to reach the cecum and in endoscopic therapy for gastrointestinal bleeding. The 14 attendees from Ghana, Côte D'Ivoire, and Nigeria included novices and experienced endoscopists.

The course was held in an ex-vivo laboratory featuring synthetic, porcine, and bovine endoscopy models, and also clinical procedures were also attended along with faculty. Over the 4 days of the course, the attendees improved their colonoscopy skills and many performed their first variceal band ligation procedures. Some attendees also learned esophageal dilation and stent placement techniques.

The WGO was represented by Dr. Eamonn Quigley and Dr. Damon Bizos; other faculty included Dr. Rudolph Darko (of the Korle Bu Department of Surgery) and doctors Joseph Kolars, Lewis Roberts, Robert Sedlack, and Mark Topazian of the Mayo Clinic, Rochester, Minnesota. Endoscopy equipment and accessories were provided by Olympus KeyMed, Karl Storz Endoscopy, and Cook Medical. The aid organization International Aid (Spring Lake, Michigan) provided laboratory and teaching space in the Korle Bu Surgical Skills Training Center.

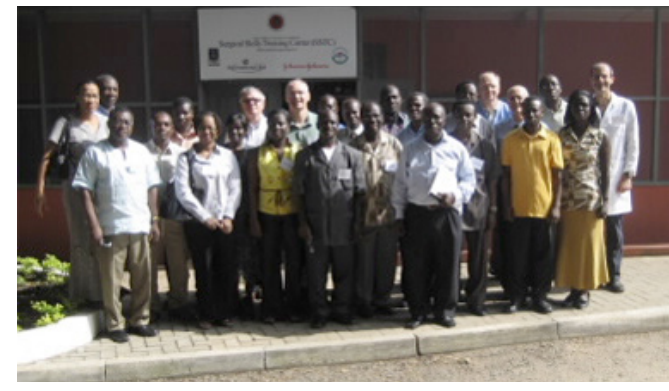

Course attendees in front of the Korle Bu Surgical Skills Training Center.

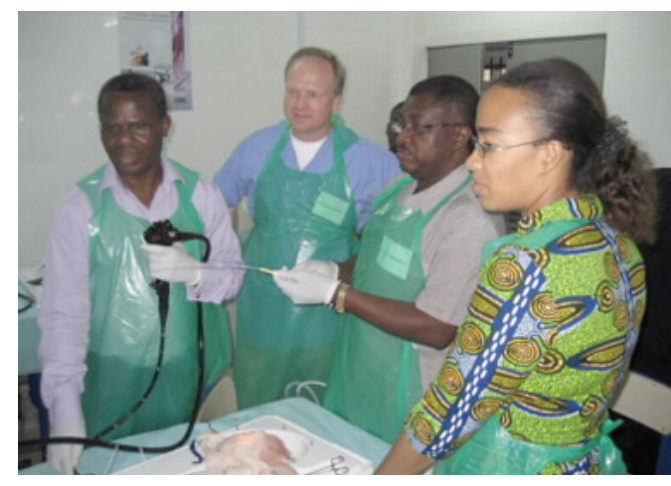

Dr. Sedlack teaches colonoscopy in the ex-vivo laboratory.

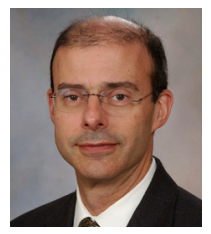

Mark Topazian, MD

Division of Gastroenterology and Hepatology, Mayo Clinic, 200 First Street SW, Rochester, MN 55905, USA. 


\title{
World Digestive
}

\author{
Health Day
}

May 29, 2009

Irritable Bowel

Syndrome

\section{IBS: The Hidden Disease}

700 million people worldwide are affected

by irritable bowel syndrome but yet $90 \%$ of IBS sufferers do not seek medical care.

As many as $65 \%$ of children with frequent abdominal pain actually have irritable bowel syndrome
Sufferers report a staggering 34\% loss of overall work productivity - equivalent to almost 14 hours per week
$90 \%$ of people who suffer from long-term symptoms do not seek medical advice and are left undiagnosed

It is now recognized that Irritable Bowel Syndrome (IBS) is a truly global problem reportedly affecting millions of individuals worldwide and exerting a significant influence on the quality of life both for the many reported and unreported cases. Yet, despite volumes of research highlighting the prevalence and impact of IBS worldwide, IBS remains poorly understood by the medical community and the general public alike.

WGO recognises therefore, that there exists a very significant "knowledge gap" with regard to all aspects of IBS and there is a real unmet need to bring the very latest information on IBS to medical practitioners, other health care workers and the general public. For this reason, WGO, in partnership with industry sponsors, focuses the attention of the global gastroenterology community on May 29, 2009 on IBS. 
World Digestive Health Day:

May 29, 2009

\section{Irritable Bowel Syndrome}

WGO calls upon all members of the global gastroenterology community to raise awareness about IBS amongst their colleagues, patients and staff.

\section{IBS Tools}

WGO has put together a collection of tools to help you raise awareness about IBS.

\section{Tools for Doctors:}

- IBS Guideline

- Test for diagnosing IBS

- Questions patients ask about IBS

- Review of the best articles published about IBS, our "Monthly Research Review" service

Do you have patients who need more information about digestive health? WGO has put together tools to help you address these needs.

Tools for Patients:

- Edu-lessons about digestive health

- Online test to help patients evaluate and improve their digestive health

Access the tools online:

http://www.worldgastroenterology.org/wdhd-2009.html http://www.wgofoundation.org/wdhd-2009.html

\section{WDHD EVENTS AROUND THE WORLD TAKE PLACE ON SIX CONTINENTS:}

1. Argentina: La Plata

2. Argentina: Mar del Plata

3. Australia: Toowoomba

4. Belarus: Minsk

5. Chile: Santiago de Chile

6. Greece: Athens

7. Guatemala

8. India: Bhubaneswar

9. India: Pune

10. Indonesia: Jakarta

11. Iran

12. Jordan: Amman

13. Malaysia: Selangor

14. Mexico: Mexico DF

15. Nepal: Dharan

16. Nicaragua: Managua
17. Pakistan: Peshawar

18. Pakistan: Lahore

19. Saudi Arabia: Kauh

20. Saudi Arabia: Riyadh

21. Slovakia: Bratislava

22. South Africa: Johannesburg

Durban, Cape Town

23. Spain: Granada

24. Sudan: Khartoum

25. Ukraine: Kyiv

26. United Arab Emirates: Abu Dhabi

27. Uruguay: Montevideo

28. USA: Cincinnati

29. Venezuela: Caracas,

Maracaibo, Barquisimeto

30. Yemen: Sana'a

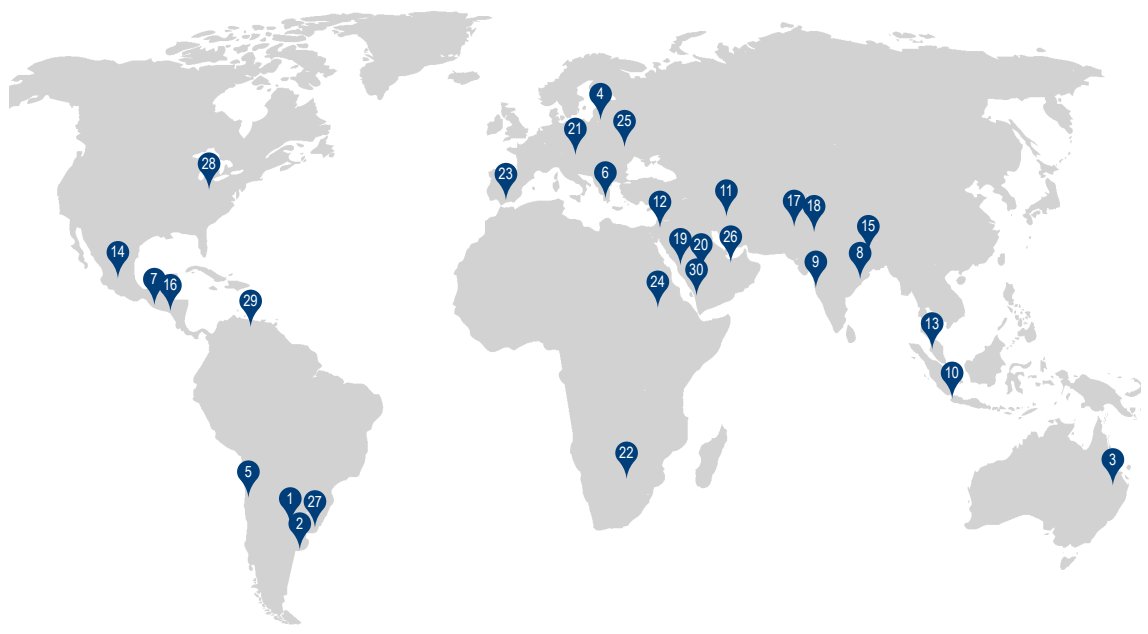

\section{HIGHLIGHTS OF WORLD DIGESTIVE HEALTH DAY}

Toowoomba, Australia: May 25-29

World Gastroenterology Awareness week

Pune, India: May 29

An IBS-awareness campaign for the general public and the medical

Fraternity. Related to the website www.ibspune.net

Darfur, Sudan: May 28-29

IBS Symposium

Kiev, Ukraine: May 29

World Digestive Health Day Conference for health care professionals

Cincinnati, USA:

WGO Summit Task Force opens with a meeting on "A Global Perspective on IBS"

Caracas, Maracaibo and Barquisimeto in Venezuela: May 29

Street events, speeches, infomercials and discussions on World

Digestive Health Day

Iran: May 21-29

A series of seminars, radio and TV programs will take place during the World Digestive Health Week 


\title{
What do we know about IBS in Mexico?
}

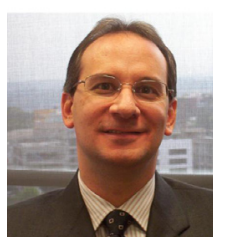

\author{
Max Schmulson, MD
}

Laboratorio de Hígado, Páncreas y Motilidad (HIPAM), Departamento de Medicina Experimental, Facultad de Medicina, Universidad Nacional Autónoma de México / Hospital General de México, Dr. Balmis \#148. Col. Doctores C.P.06726, Mexico

In the past few years, there has been considerable interest in irritable bowel syndrome (IBS) in Mexico, possibly due to the development of the Rome criteria. There has been an increase in the number of studies on the topic presented annually at the Mexican National Gastroenterology Week and in the number of reports on it in the Revista de Gastroenterología de México (the Mexican gastroenterology journal) and other international publications.

\section{Epidemiological data}

Recent studies have led to a better understanding of the epidemiology of IBS in Mexico. In a communitybased study using the Rome II criteria, conducted in the state of Tlaxcala in central Mexico, IBS was found to have a prevalence of $16 \%$ [1]. By contrast, in another study among volunteers from a university population in the south of Mexico City, the frequency of IBS was $35 \%$ [2]. Between $70 \%$ and $80 \%$ of those who met the criteria for IBS were female. In these studies, IBSC (constipation-predominant) was more frequent than IBS-D (diarrheapredominant) [1,2]. More recently, in a study that included more than 2400 private-practice patients nationwide, using the Rome III criteria, 49\% were classified as having IBS-M (mixed), 42\% as having IBS-C, $6 \%$ as having IBS-D and $3 \%$ as having IBS-U (unsubtyped) [3]. The higher frequency of constipationpredominant IBS in comparison with the diarrhea-predominant form has been confirmed in an international study that compared symptoms in eight countries (USA, Mexico, Canada, England, Italy, Israel, India and China) [4].

In Mexico, IBS is the first reason for consulting a gastroenterologist in approximately $23 \%$ of cases. The main reasons patients consult are pain/abdominal discomfort, symptoms brought on by stress, impairment of everyday activities, and (in a smaller proportion) fear of cancer [5]. However, bloating and abdominal distension are considered the most bothersome symptoms. In fact, Mexican patients report higher bloating scores in comparison with patients in other countries [4]. We have also observed that patients aged 30-50 who seek medical attention report pain and abdominal bloating during the previous week significantly more intense than that reported by patients younger than 30 and older than 50 . This may explain the higher rate of consultation for IBS symptoms during the fourth decade of life [6].

Patients in Mexico also consulted three or four times per year, in comparison with non-IBS patients who do so only about twice a year, and they seek medical attention for both gastrointestinal and nongastrointestinal symptoms, leading to a high rate of unnecessary diagnostic testing [7]. Even after IBS has been diagnosed using the accepted criteria, excessive numbers of diagnostic evaluations are still ordered. It has been shown that if minimum workup is done, as recommended by the various guidelines available such as the Latin American Consensus on IBS, there would be considerable economic savings (66\% and 95\%) [8]. Another point that stands out is the high rate of abdominal surgery in our patients. For example, appendectomies are 16 times more likely and cholecystectomies are 2.5 times more frequent among IBS patients than in those discharged after treatment for other conditions [7]. In our experience, one of the reasons for the excess of consultations is the lack of an effective treatment for IBS. It could also be due to the lack of information and reassurance provided by physicians. In fact, we have proved that the simple intervention of providing better information can acutely modify patients' perception of their degree of impairment in daily life [5].

\section{Health-related quality of life (HRQOL)}

It is known that IBS patients' quality of life is reduced in comparison with the general population, at a rate similar to that patients with chronic renal failure or those with liver problems due to hepatitis $\mathrm{C}$. In addition, the impact of IBS on the HRQOL in female patients is greater than that reported by female patients in other countries with regard to body image, concern about health, and interference with everyday activities [9]. Some factors, such as fear of cancer, impairment of everyday activities, and symptom-related stress may also influence the HRQOL [5].

\section{Postinfectious IBS and other comorbidities}

There are insufficient data about the frequency of postinfectious IBS in Mexico. A small retrospective study reported a frequency of less than $6 \%$ [10]. However, it is known that among American students who visit Mexico for short periods, all of those who developed IBS after returning home had had traveler's diarrhea, in comparison with only half of those who did not develop IBS [11].

In relation to other comorbidities, up to $48 \%$ of patients who meet the criteria for IBS report heartburn, and more than half report symptoms of dyspepsia [12]. In addition, $70 \%$ of patients have anxiety, $46 \%$ have depression, and $40 \%$ have both. These findings are associated with a larger number of days with abdominal pain/discomfort per week and the perception of having a more severe disease [13]. Fibromyalgia is much 
less frequent than has been reported in other countries; however, the overall prevalence of fibromyalgia appears to be lower in Mexico [14].

\section{Beliefs about IBS in Mexico}

As part of a cross-cultural study that is in progress, we have informally interviewed IBS patients, their relatives, and health professionals, and have found that IBS is perceived in Mexico not as an illness, but as a problem of "psychosomatic origin" exacerbated by factors involved in food and family relationships [15]. Despite this, there is considerable resistance to consulting a psychotherapist and to the use of antidepressants, as the disease might then be viewed as a mental illness or a form of "madness." There is a common belief that IBS is more frequent among women, because they are more "open to discussing the subject," while men are more "ashamed" of suffering these symptoms and therefore joke about it. The patients' reference to family factors represents an ingrained cultural factor in which the individual is seen as part of a family unit, with personal health being affected by interpersonal relationships, consistent with previous findings in IBS [15]. Also, the lack of an effective treatment leads some patients to seek treatment with alternative or complementary medicine. A study from San Luis Potosi has reported that half of the patients used these treatments, in which herbal preparations are the most commonly used agents [16].

\section{The Future}

Research is now being conducted in Mexico to investigate genetic associations in IBS, the translation and validation of the more recent Rome III criteria, and studies to evaluate treatments that are commonly used but have not been investigated (at least according to the currently accepted guidelines for clinical studies in functional gastrointestinal disorders). Considerable efforts are being made to educate health-care professionals about the latest concepts of diagnosis and treatment of IBS.

\section{References}

1. Lopez-Colombo A, Bravo-Gonzáles D, Corona-Lopez A, et al. First communitybased study of functional gastrointestinal disorders (FGID) in México using the Rome II modular questionnaire [abstract]. Gastroenterology 2006;130(Suppl 2):A-508.

2. Schmulson M, Ortíz O, Santiago-Lomeli $\mathrm{M}$, et al. Frequency of functional bowel disorders among healthy volunteers in Mexico City. Dig Dis 2006;24:342-7.

3. Schmulson M, Lopez-Alvarenga JC, Vargas J, et al. Clinical differences in irritable bowel syndrome (IBS) subgroups according to Rome III criteria. A preliminary report of the Mexican IBS working group. Neurogastroenterol Motil 2008;20(Suppl 1):138.

4. Gerson CD, Gerson MJ, Awad RA, et al. Irritable bowel syndrome: an international study of symptoms in eight countries. Eur J Gastroenterol Hepatol 2008;20:659-67.

5. Schmulson M, Ortiz O, Hinojosa C, Arcila D. A single session of reassurance can acutely improve the self-perception of impairment in patients with IBS. J Psychosom Res 2006;61:461-7.

6. Remes-Troche JM, Valdovinos MA, Hinojosa C, Schmulson MJ. IBS patients differ according to age: Self-reported symptom severity is related. Am J Gastroenterol 2003;98(Suppl):S268.

7. Schmulson M, Valdovinos MA. Utilización de los recursos médicos por los pacientes con síndrome de intestino irritable en un hospital de tercer nivel. Rev Gastroenterol Mex 1998;63:6-10.

8. Schmulson M. El escrutinio diagnóstico limitado puede disminuir el impacto económico directo del síndrome de intestino irritable (SII). Rev Med Chile 2008;136:1398-405.

9. Schmulson M, Ortiz O, Mejia-Arangure $\mathrm{JM}$, et al Further validation of the IBS-QOL: female Mexican IBS patients have poorer quality of life than females from North Carolina. Dig Dis Sci 2007;52:2950-5.
10. Ortiz OM, Remes-Troche JM, Valdovinos MA, Vargas-Voráckova F, Schmulson M. Frecuencia de factores desencadenantes extero e interoceptivos en la presentación inicial del síndrome de intestino irritable (SII) en un hospital de tercer nivel en México: Baja frecuencia de de SII postinfeccioso? Rev Gastroenterol Mex 2003;68(Suppl 2):98-9.

11. Okhuysen PC, Jiang ZD, Carlin L, Forbes C, DuPont HL. Post-diarrhea chronic intestinal symptoms and irritable bowel syndrome in North American travelers to Mexico. Am J Gastroenterol 2004;99:1774-8.

12. Schmulson $M$, Pulido $D$. The frequency of functional heartburn $(\mathrm{FH})$ and other gastroesophageal reflux (GER) symptoms in subjects with IBS in the community, is higher than that of the controls, and more likely among those with an abnormal body mass index [abstract]. Gastroenterology 2008;134(Suppl 1):A-719.

13. Reséndiz-Figueroa FE, OrtizGarrido OM, Pulido D, Arcila-Martínez D, Schmulson M. [Impact of the anxiety characteristics and depression on clinical aspects and quality of life in patients with irritable bowel syndrome.] Rev Gastroenterol Mex 2008;73:3-10.

14. Remes Troche JM, Peláez M, Nigl I, Valdovinos MA, Schmulson M. Características clínicas de pacientes mexicanos con síndrome de intestino irritable (SII), moderado a grave, de acuerdo al hábito intestinal y el género. Rev Gastroenterol Méx 2002;67(Suppl. 3):205.

15. Schmulson M. Irritable bowel syndrome (IBS) in Mexico. Cross-cultural column. Functional Brain-Gut Research Group Newsletter, Spring 2007;38:8-9.

16. Carmona-Sánchez R, TostadoFernández FA. Prevalence of use of alternative and complementary medicine in patients with irritable bowel syndrome, functional dyspepsia and gastroesophageal reflux disease. Rev Gastroenterol Mex 2005;70:393-8. 


\title{
Current challenges in diagnosing and treating IBS:
}

\author{
The importance of a positive \\ diagnosis and a graded general \\ treatment approach
}

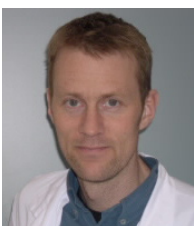

Per Olav Vandvik, MD

Consultant Physician, Department of Gastroenterology, Innlandet Hospital Health Authority, Gjøvik, Norway/ Associate Professor, Faculty of Medicine, University of Oslo

Although there is more that we need to

factors interacting via the brain-gut learn more about the etiology of IBS, this should not keep us from providing nearly half of our patients with optimal care. Clinical guidelines set high standards for the diagnosis and treatment of IBS. This review aims to provide gastroenterologists with an update on some key elements and challenges.

\section{Optimal management of IBS- why bother?}

IBS is the most common gastrointestinal disorder in the population, both in primary care and in specialist health care. Although not all patients will consult for IBS and most consulters are handled by family practitioners, patients with IBS constitute $30-50 \%$ of the workload at gastroenterology outpatient clinics [1]. The subset who are referred to gastroenterologists represents only the "tip of the iceberg" of IBS, characterized by more pronounced symptom intensity and higher levels of psychosocial problems than patients in primary care [2]. IBS is also associated with a markedly reduced quality of life and high utilization of health-care resources $[1,3]$.

Irritable bowel syndrome (IBS) is an enigma. The Rome III Committee defines IBS as a functional gastrointestinal disorder: symptoms of IBS represent the clinical product of altered gut physiology and psychosocial axis. Research on IBS is flourishing, with the annual number of publications in PubMed exceeding 500 in 2005. In particular, research on the basic pathophysiological mechanisms involved and on drugs targeted towards the gastrointestinal tract is receiving significant attention. Some experts believe IBS will turn out to represent a series of poorly understood organic diseases [4]. Others caution against this "organification" of IBS and find it unlikely that an altered gene or set of specific biological etiologies will explain a complex brain-gut disorder such as IBS [5]. One phenomenon to support this cautious approach is the "comorbidity" aspect of IBS: patients with IBS report other gastrointestinal symptoms (such as heartburn and dyspepsia), somatic symptoms (such as musculoskeletal pain and headache), and psychiatric symptoms (anxiety and depression) more often than those without IBS $[6,7]$. Referred patients have the highest levels of comorbid symptoms and disorders. In contrast to the Rome III report, recent evidence shows that somatic and psychiatric comorbidity is a feature of IBS and not only of those with the condition who consult physicians [7]. The etiological implications of the observed comorbidity need further elucidation. The comorbidity of IBS also explains a large part of the reduced quality of life and increased use of health resources hitherto attributed to IBS [1,7]. Optimal care for patients with IBS will therefore often require physicians to look beyond the gastrointestinal tract. The comorbidity of IBS underlines the need for continuous and optimal care to be delivered to these patients by family practitioners. This report will focus on what gastroenterologists can do in clinical encounters with referred patients.

\section{Making a positive diagnosis}

In the absence of a biological marker, diagnosing IBS continues to be a challenge. Nevertheless, all guidelines recommend that IBS can and should be made as a positive, symptom-based diagnosis $[8,9]$. This approach requires a careful interpretation of the temporal relationship between abdominal pain/ discomfort, bowel habit, and stool characteristics. Diagnostic criteria

Table 1. Diagnostic criteria* for irritable bowel syndrome.

\begin{tabular}{|l|}
\hline $\begin{array}{l}\text { Recurrent abdominal pain or discomfort } \\
\text { last } 3 \text { months associated with two or more of the following: }\end{array}$ \\
\hline 1. Improvement with defecation \\
\hline 2. Onset associated with a change in frequency of stool \\
\hline 3. Onset associated with a change in form (appearance) of stool \\
\hline
\end{tabular}

* Criteria must have been fulfilled for the previous 3 months, with symptom onset at least 6 months before diagnosis.

† Discomfort means an uncomfortable sensation not described as pain. In pathophysiology research and clinical trials, a pain/discomfort frequency of at least 2 days a week is required during screening evaluation for patients to be eligible for inclusion. 
Table 2. Guidelines for establishing a therapeutic physician-patient relationship.

\begin{tabular}{|c|}
\hline $\mathrm{w}$ \\
\hline Conduct a careful examination and cost-efficient investigation \\
\hline $\begin{array}{l}\text { Determine how much the patient understands about the illness and what his or her concerns } \\
\text { are ("What do you think is causing your symptoms?") }\end{array}$ \\
\hline $\begin{array}{l}\text { Provide a thorough explanation of the disorder that takes into consideration the patient's } \\
\text { beliefs }\end{array}$ \\
\hline $\begin{array}{l}\text { Identify and respond realistically to the patient's expectations for improvement ("How do you } \\
\text { feel I can be helpful to you?") }\end{array}$ \\
\hline $\begin{array}{l}\text { When possible. provide a link between stressors and symptoms that are consistent with } \\
\text { the patient's beliefs-("I understand you don't think stress is causing your pain, but the pain } \\
\text { itself is so severe and disabling that it's causing you a great deal of distress") }\end{array}$ \\
\hline $\begin{array}{l}\text { Set consistent limits ("I appreciate how bad the pain must be, but narcotic medication is not } \\
\text { indicated") }\end{array}$ \\
\hline Involve the patient in the treatment ("Let me suggest some treatments for you to consider") \\
\hline $\begin{array}{l}\text { Make recommendations consistent with the patient's interests ("Antidepressants can be } \\
\text { used for depression, but they are also used to 'turn down' the pain and in doses lower than } \\
\text { those used for depression") }\end{array}$ \\
\hline \\
\hline
\end{tabular}

have been established to facilitate a symptom-based diagnosis, with the Rome III criteria for IBS representing the latest revision (Table 1). The new criteria only feature minor changes from the Rome II list, including a simplified time frame and a subtype classification based on stool consistency. These criteria and a novel diagnostic questionnaire developed by a validation process can easily be downloaded from www.romecriteria.org. As acknowledged by the authors, the criteria are imperfect and there is a great need to generate data that will sharpen the criteria and validate their use in clinical practice. Interestingly, few if any studies have looked at how such criteria should be used in busy clinical practices $[10,11]$. However, the success of a positive diagnosis probably relies more on gastroenterologists' attitudes and knowledge than on the strict use of criteria.

The positive symptom-based approach is preferred because it allows explanation, reassurance and education of the patient and reduces the need for costly and potentially harmful diagnostic evaluations $[9,12]$. Indeed, a confident diagnosis may be the physician's most important therapeutic tool and is considered a cornerstone in the general treatment approach (see below). Importantly, although this approach differs from a traditional "diagnosis of exclusion" approach, it does not rule out the need for additional investigations before a diagnosis of IBS is reached in every patient.

\section{Providing a graded general treatment approach}

In a harmless disorder such as IBS, symptoms may range from negligible to incapacitating. In the absence of curative treatment, symptomatic and supportive treatment is the goal. The guidelines recommend a graded general treatment approach, key elements of which are a strong physician-patient relationship, assessment of psychosocial factors, and targeted treatment in selected patients $[8,9]$.

The establishment of a strong and therapeutic patient-physician relationship hinges on thorough evaluation and on reassurance and education of the patient. The patient-physician encounter in IBS is challenging and can be frustrating to both parties. As the guidelines in Table $\mathbf{2}$ show, a structured approach is therefore recommended for establishing a therapeutic relationship.
A quick look at these guidelines shows that gastroenterologists need to invest both time and interest. A therapeutic relationship will facilitate the assessment of psychosocial factors, which should include symptoms of depression and anxiety, somatic comorbid symptoms, health beliefs, coping, illness impact, and healthrelated quality of life. Another important dimension is the exploration of chronological "coincidences" between psychosocial factors and periods of worsening or improving symptoms. In patients with severe symptomatology, referral to a skilled psychiatrist or psychologist can be useful. Rome III suggests "red flags" for consideration of early referral to a mental health care provider. In addition to severe depression, some other red-flag items include chronic refractory pain, severe disability, and difficulties in physicianpatient interaction.

Patient education is facilitated by written materials, which can be effective interventions in themselves. In patients with IBS in the United Kingdom, a selfhelp handbook reduced the use of health care and of perceived symptom severity [13]. We should make such handbooks available to our patients. In my experience, patients warmly welcome detailed information, and such books reduce my workload. Some of these books can also be recommended for physicians. I have learnt a lot from reading Nicholas Talley's Conquering Irritable Bowel Syndrome [14].

Whereas patients with mild symptoms are likely to benefit from the above general treatment approach, patients with more severe symptoms will often need targeted treatment for their most troublesome symptoms. A detailed review of such treatment is beyond the scope of this report. In general, drugs help only some symptoms in selected patients, and there is a notable placebo effect. Novel drug treatments such as serotoninreceptor agonists and antagonists display have been disappointing, and they are unavailable in most European countries. While we are waiting 
for more effective drugs for IBS, gastroenterologists need to provide patients with proven effective drug treatment. Such treatment includes tricyclic antidepressants in low doses for abdominal pain, loperamide for diarrhea/urgency, and soluble fiber for constipation [15-18].

Mind-body treatment (psychological intervention) is also effective in IBS, although there is a shortage of highquality evidence [16]. Treatment modalities include gut-focused hypnotherapy, cognitive behavioral therapy (CBT), stress relaxation therapy, and interpersonal therapy. In particular, hypnotherapy and CBT have demonstrated beneficial effects in severely affected patients in clinical trials [19]. The advantages of mindbody treatment include efficacy in relation to comorbid conditions in IBS, its absence of adverse effects, and the shift of the locus of control so that patients themselves may feel more able to cope with the symptoms. If the goal is global improvement of patients' lives and reduction of health-resource use, then mind-body treatment should more often be the treatment of choice. A major challenge is that such treatment is resource-demanding and that it requires highly skilled therapists interested in IBS. In my experience, these therapists are not easy to find.

\section{How are we performing today? Is it time to change our practices?}

The recommendations for the diagnosis and treatment of patients with IBS made by Rome III are by no means revolutionary $[20,21]$. One would therefore expect these recommendations to be widely implemented in clinical practice. Unfortunately, evidence suggests that this is not the case and that we have a long way to go.

We need to improve physicians' knowledge and attitudes towards functional gastrointestinal disorders.
Many gastroenterologists still view functional gastrointestinal disorders as psychological disorders, or merely as an absence of organic disease, while others deny the existence of functional gastrointestinal disorders. Gastroenterologists often ascribe pejorative characteristics to the patient or show negative attitudes during patient encounters [8]. Rome III strongly advocates proper education of physicians, stating that functional gastrointestinal disorders should be prominent parts of undergraduate and postgraduate medical curricula, clinical training programs, and international symposia. There is probably a significant gap between these recommendations and current educational efforts in gastroenterology worldwide. As a hospital physician, I knew next to nothing about IBS before I became involved in IBS research.

We need to organize our clinical practice to set the scene for optimal diagnosis and treatment. Gastroenterology outpatient practice probably varies across countries all over the world. In Norway, gastroenterologists most often choose to perform a colonoscopy in these patients, based on a short referral note from the family practitioner. Accordingly, patients' first (and perhaps only) clinical encounter with a gastroenterologist is when they are lying on the endoscopy table with their bowels emptied and anus facing the gastroenterologist. This is not the optimal setting for making a positive diagnosis and providing a general treatment approach! In addition, drugs administered before the endoscopic examination may affect patients' memory and further diminish the value of a clinical consultation, which sometimes follows after the colonoscopy. Many gastroenterologists are strong believers in the therapeutic value of a colonoscopy with negative findings, but this belief is not supported by research evidence. In other words, it seems obvious that we need to reorganize practice if we are aiming to provide patients with the optimal care outlined above. Perhaps we should start with a well-conducted clinical consultation in patients with symptoms suggestive of IBS. In harmony with the principles of evidence-based health care, this approach would allow clinical expertise to be combined with patients' preferences in the diagnostic evaluation. In a young patient with typical symptoms of IBS, a fecal calprotectin test might be sufficient to rule out inflammatory bowel disease [22]. Although some patients would need to come back for a colonoscopy, it is likely that a significant proportion of colonoscopies would be avoided. Gastroenterologists will, quite understandably, fear missed organic disease and an increased workload with this approach. We therefore need high-quality research evidence that this approach is reliable in terms of diagnostic validity and cost-effective in terms of relevant patient outcomes and health-resource usage. Although all existing evidence supports an approach based on a positive diagnosis and general treatment, there is urgent need for clinical research to improve the evidence base.

In conclusion, gastroenterologists face significant challenges in the clinical management of patients with IBS. The road from best evidence to best practice is seldom straightforward and involves many factors other than drawing up guidelines. For gastroenterologists, the first and crucial step on this road is to recognize that a confident diagnosis and a graded general treatment approach could be the best treatment we currently have to offer for many of our patients with IBS. 


\section{References}

1. Chang L. Epidemiology and quality of life in functional gastrointestinal disorders. Aliment Pharmacol Ther 2004;20(Suppl 7):31-9.

2. Koloski NA, Talley NJ, Boyce PM. Predictors of health care seeking for irritable bowel syndrome and nonulcer dyspepsia: a critical review of the literature on symptom and psychosocial factors. Am J Gastroenterol 2001;96:1340-9.

3. Camilleri M, Williams DE. Economic burden of irritable bowel syndrome. Proposed strategies to control expenditures. Pharmacoeconomics 2000;17:331-8.

4. Talley NJ, Spiller R. Irritable bowel syndrome: a little understood organic bowel disease? Lancet 2002;360:555-64.

5. Drossman DA. The "organification" of functional GI disorders: implications for research. Gastroenterology 2003;124:6-7.

6. Whitehead WE, Palsson O, Jones KR. Systematic review of the comorbidity of irritable bowel syndrome with other disorders: what are the causes and implications? Gastroenterology 2002;122:1140-56.

7. Vandvik PO, Lydersen S, Farup PG. Prevalence, comorbidity and impact of irritable bowel syndrome in Norway. Scand J Gastroenterol 2006;41:650-6.

8. Drossman DA. The functional gastrointestinal disorders and the Rome III process. Gastroenterology 2006;130:1377-90.
9. Spiller R, Aziz Q, Creed F, et al.

Guidelines on the irritable bowel syndrome: mechanisms and practical management. Gut 2007;56):1770-98.

10. Agreus L. Rome? Manning? Who cares? Am J Gastroenterol 2000;95:2679-81.

11. Ford AC, Talley NJ, Veldhuyzen van Zanten SJ, Vakil NB, Simel DL, Moayyedi $P$. Will the history and physical examination help establish that irritable bowel syndrome is causing this patient's lower gastrointestinal tract symptoms? JAMA 2008;300:1793-1805.

12. Longstreth GF, Thompson WG, Chey WD, Houghton LA, Mearin F, Spiller RC. Functional bowel disorders. Gastroenterology 2006;130:1480-91.

13. Robinson A, Lee V, Kennedy A, et al. $A$ randomised controlled trial of self-help interventions in patients with a primary care diagnosis of irritable bowel syndrome. Gut 2005;55:643-8.

14. Talley NJ. Conquering irritable bowel syndrome: a guide to liberating those suffering with chronic stomach or bowel problems. Hamilton, ON: Decker; 2006.

15. Camilleri M. Clinical evidence to support current therapies of irritable bowel syndrome. Aliment Pharmacol Ther 1999;13(Suppl 2):48-53.
16. Ford AC, Talley NJ, Schoenfeld PS, Quigley EM, Moayyedi P. Efficacy of antidepressants and psychological therapies in irritable bowel syndrome: systematic review and meta-analysis. Gut 2009;58:367-78.

17. Ford AC, Talley NJ, Spiegel BM, et al. Effect of fibre, antispasmodics, and peppermint oil in the treatment of irritable bowel syndrome: systematic review and meta-analysis. BMJ 2008;337:a2313.

18. Jailwala J, Imperiale TF, Kroenke $K$. Pharmacologic treatment of the irritable bowel syndrome: a systematic review of randomized, controlled trials. Ann Intern Med 2000;133:136-47.

19. Levy RL, Olden KW, Naliboff BD, et al. Psychosocial aspects of the functional gastrointestinal disorders. Gastroenterology 2006;130:1447-58.

20. Jones J, Boorman J, Cann P, et al. British Society of Gastroenterology guidelines for the management of the irritable bowel syndrome. Gut 2000;47(Suppl 2):ii1-19.

21. Drossman DA, Camilleri M, Mayer EA, Whitehead WE. AGA technical review on irritable bowel syndrome. Gastroenterology 2002;123:2108-31.

22. Tibble JA, Sigthorsson G, Foster R, Forgacs I, Bjarnason I. Use of surrogate markers of inflammation and Rome criteria to distinguish organic from nonorganic intestinal disease. Gastroenterology 2002;123:450-60. 


\section{Interview with Professor Zaigham Abbas: IBS in Asia}

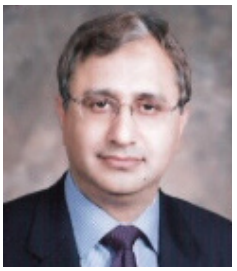

Prof. Zaigham Abbas of the Sindh Institute of Urology and Transplantation, Karachi, is a member of the team that put together the World Gastroenterology Organisation guideline on Irritable Bowel Syndrome (IBS) (see previous article). Dr. Abbas responded to questions about IBS in Pakistan, the importance of resource-based guidelines, and the work that goes into producing a WGO guideline.
WGN: The World Gastroenterology Organisation tries to take account of regional differences when making guidelines. These differences may be cultural, ethnic, epidemiological, or resource-based. Is IBS in Pakistan different from IBS in Europe?

Prof. Abbas: IBS is the most common functional disorder seen in our gastroenterology clinics. The estimated prevalence of IBS in the Pakistani population is $10-15 \%$. However, it is not a female-dominated problem, as we see more men than women. It is common in young and middle-aged adults. One reason for the male predominance might be that male patients with IBS seek medical advice more actively in comparison with women, who feel uncomfortable about describing their bowel function to medical personnel. These patients present with upper, mid- or lower abdominal pain and/or bloating. Their symptoms improve with defecation. Diarrhea-predominant IBS (IBS-D) is more common in Pakistan.

WGN: The prevalence of irritable bowel syndrome in any defined population depends on which criteria (for prevalence) are applied: the Kruis scoring system, the Manning criteria, or the ROME-I, ROME-II, or ROMEIII criteria. There are those who say we should now discard Rome. What relevance do these remarks have for Pakistan?
ZA: Various attempts have been made to group together patients presenting with lower gastrointestinal symptoms in the absence of "red flag" signs and organic disease. The symptoms are abdominal pain, discomfort and fullness, bloating, a feeling of incomplete evacuation, straining, postprandial bowel movements, altered frequency or consistency, pain relief with defecation, and presence of mucus. There are various combination patterns, which may vary from region to region and from East to West. The component of abdominal pain emphasized in the Rome criteria is often missing. A feeling of incomplete evacuation is taken by many patients to be constipation, although their frequency may be more than once a day to overcome this. It has already been reported that switching from the Rome II to Rome III criteria increases the prevalence of IBS. Recently, our understanding of IBS has significantly changed. In addition to the brain-gut axis, dysmotility, and visceral hypersensitivity, we are now implicating bacterial and protozoal infections, microinflammation, and cytokines. In countries like Pakistan, where self-medication is not uncommon, it is not unusual to see patients with IBS stating that their symptoms improve after taking Flagyl (metronidazole) for 1-2 days. Due to the heterogeneity of the precipitating factors and symptoms, it's my "gut" feeling that instead of following a particular definition, we should keep an open mind, perhaps by introducing new terminology like "irritable bowel overlap syndromes" (IBOS).

WGN: A recent study from India (PMID 18541934) argues that we should be mindful of "patient-centered" criteria. Key symptoms such as diarrhea, constipation, bloating, and pain are subjective; in India, these are not captured adequately by the Rome criteria. The study suggests that the cultural background may affect which symptoms are reported and how they are reported. What is the relevance of these remarks for Pakistan?

ZA: In Pakistan, people are more concerned about bloating rather than pain, more with upper abdominal than lower abdominal pain, and more with a feeling of incomplete evacuation rather than true constipation. The presence of mucus, postprandial bowel movements, and clustering of bowel movements in the morning in IBS-D are typical.

WGN: As you know, WGO has developed the concept of cascadesresource-sensitive options for diagnosis and treatment. This is because diagnostic and management resources differ between countries and even within countries. How helpful is this concept for you?

ZA: The WGO practice guidelines are written from a viewpoint of global 


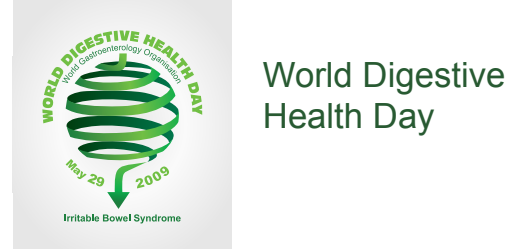

applicability and are cascade-based. The cascades rank different treatment options for diagnosis and treatment, depending on the resources available. Many developing countries have limited resources. Guidelines from the developed world become irrelevant if the latest investigational tools and treatment options recommended in the guidelines are not available. By developing cascades, we try to match options for diagnosis and treatment with the resources available in less privileged areas of the world, while keeping the recommendations as evidence-based as possible. We may incorporate the level of evidence into cascades, but I don't feel that this is necessary.

WGN: Your contribution to the WGO's IBS guideline included very important elements for the IBS diagnostic and management cascades. It is a very creative process - can you tell us a little bit more about working on the cascades?

ZA: When you are working in a developing country, you know the limitations, and cascades address these limitations. In the case of IBS, we always emphasize the need for effective physician-patient relationships, which do not require any advanced technology but rather further education for physicians. We should also avoid a shotgun approach when ordering investigations in the absence of red-flag symptoms; limited, pertinent investigations are enough.

I am very proud to have been part of the IBS review team, and I have always enjoyed working with WGO. I have worked with IDCA, the cancer division of WGO, and I attended a Train-theTrainers workshop, in Ponta Del Este, Uruguay, in 2005. I am also a trainer at the WGO Training Center in Karachi.

WGN: One complaint often heard is that the usual "gold standard" guidelines from the major medical societies follow evidence-based criteria, but do not take account of the resources available in other parts of the world. Do you have any examples that would demonstrate to our readers that "one-size-fits-all" guidelines from Europe or the USA do not apply $100 \%$ in Pakistan?

ZA: An example of this is the hepatitis $B$ guidelines. In all the guidelines, it is emphasized that patients should be treated only if the alanine aminotransferase (ALT) level is more than two times the upper limit of normal and the viral load is over 20,000 IU for $\mathrm{HB}_{\mathrm{e}} \mathrm{Ag}$-positive patients and $2000 \mathrm{IU}$ in $\mathrm{HB}_{\mathrm{e}} \mathrm{Ag}$ negative patients. In Asia, we do see progression of liver disease below the limits set in these guidelines. This issue has been raised at international meetings by Asian experts, who presented evidence of differences from the Western perceptions. Now I can see a positive change in the recent European Association for the Study of the Liver (EASL) guidelines, which recommend that patients with any level of elevated ALT and a viral load over $2000 \mathrm{IU}$ should be treated, irrespective of their $\mathrm{HB}_{\mathrm{e}} \mathrm{Ag}$ status. The guidelines recommend pegylated interferon as one of the first-line agents for hepatitis $B$ treatment, but ignore the differences in the response rate depending on the viral genotype. In Pakistan, genotype $D$ is the most prevalent type; this responds poorly to the interferon therapy recommended in Western studies. So some local data are needed. Moreover, there is a possibility of variable response in subtypes of genotype D. Most of the high-quality evidence comes from the industry-funded studies, so we should not forget the possibility of publication bias.

WGN: What do you hope to have achieved 10 years from now?

ZA: I hope that in the coming years I will be able to have a more active role in WGO, helping to achieve its objectives of improving standards in gastroenterology training and education on a global scale. I hope to help raise awareness of the preventive aspects of gastrointestinal and liver diseases. And I also hope to be actively involved both in the teaching and administrative aspects of an institution fully devoted to looking after gastroenterology and liver patients. 


\section{Irritable bowel syndrome: a global perspective}

\section{(Highlights of the World Gastroenterology Organisation's newest global guideline)}

\author{
Definition: Irritable Bowel Syndrome (IBS) is a functional bowel disorder \\ in which abdominal pain or discomfort is associated with defecation or a \\ change in bowel habit; bloating, distension (in some languages, these \\ words may represented by the same term) and disordered defecation are \\ commonly associated features.
}

Review team:

Eamonn Quigley (Chairman, Ireland); Michael Fried,

K.A. Gwee, Carolina Olano, F. Guarner, I. Khalif, P. Hungin, G. Lindberg,

Z. Abbas, L. Bustos

Fernandez, F. Mearin,

S.J. Bathia, P.J. Hu,

J.H. Krabshuis,

A.W. Le Mair

\section{Introduction}

\section{IBS subclassification}

Based on the patient's specifics of their bowel habits and stool characteristics according to the Rome III criteria.

- IBS with diarrhea (IBS-D)

- Loose stools $>25 \%$ of the time and hard stools $<25 \%$ of the time

- Up to one-third of cases

- More common in men

- IBS with constipation (IBS-C)

- Hard stools $>25 \%$ of the time and loose stools < $25 \%$ of the time

- Up to one-third of cases

- More common in women

- IBS with mixed bowel habits or cyclic pattern (IBS-M)

- Both hard and soft stools $>25 \%$ of the time

- One-third to one-half of cases

It must be remembered, however that:

- Patients commonly transition between these subgroupings

- The symptoms of diarrhea and constipation are commonly misinterpreted in IBS patients. Thus, many IBS patients who complain of "diarrhea" are referring to the frequent passage of formed stools and, in the same patient population, "constipation" may refer to any one of a variety of complaints associated with the attempted act of defecation and, not simply, to infrequent bowel movements.

On clinical grounds, other subclassifications (for example based on symptoms) may be possible:
- IBS with predominant bowel dysfunction

- IBS with predominant pain

- IBS with predominant bloating

- Based on precipitating factors:

- Post-infectious IBS

- Food-induced (meal-induced)

However, the relevance of any of these latter classifications to prognosis or response to therapy remains to be defined.

It must also be remembered that Rome III criteria are not commonly used in clinical practice. Furthermore, cultural issues may inform symptom reporting. For example, in India, a patient who reports straining or passing hard stools is likely to complain of constipation even if he or she passes stools more than once daily.

\section{Global prevalence and incidence}

The prevalence of irritable bowel syndrome (IBS) is increasing in countries with developing economies. Estimates of the prevalence of IBS vary widely in the Asia-Pacific region and elsewhere, depending also on which diagnostic criteria are used (Rome I, Rome II, Rome III, Manning, Kruis).

Studies from India for example show that Rome I criteria for IBS identify more patients than Rome II criteria. Reported prevalence includes $0.82 \%$ in Beijing, $5.7 \%$ in southern China, $6.6 \%$ in Hong Kong, $8.6 \%$ in Singapore, $14 \%$ in Pakistan and $22.1 \%$ in Taiwan. A study in China found that the prevalence of IBS defined by Rome III criteria in the outpatient clinic was $15.9 \%$.

Although these values are generally lower than the prevalence of IBS in the USA (10-15\%) it is predicted that the continuing economic development of countries will give rise to changes in diet and lifestyle that may increase the incidence and diagnosis of this disorder. 


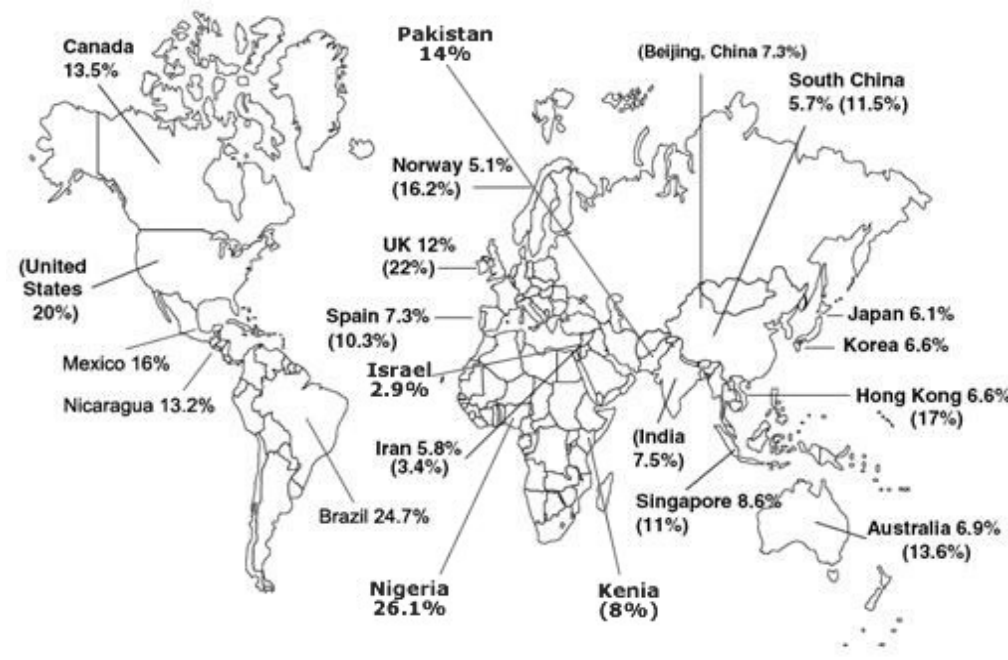

Different presenting features between East and West

- As in the case of prevalence data, global information on presenting features also varies and comparisons of studies based on community data, clinical data and hospital statistics are fraught with difficulties.

- Typical IBS symptoms are common in healthy population samples but the majority of sufferers with IBS are not actually medically diagnosed-this may explain apparent differences between countries in reported prevalence-most studies only count diagnosed IBS and not community prevalence.

- A study in China showed that the prevalence of IBS in South China was higher than that reported in Beijing, but lower than that reported in Western countries.

- Some studies in non Western countries indicate a:

- Lack of female predominance (possibly due to differences in access and health-care seeking behaviors). In South China, for example, the male to female ratio is only $1: 1.25$ (in comparison to 1:2 in Western Europe).

- Close association between marked distress and IBS in men similar to that found in women in Western studies.

- Greater frequency of upper abdominal pain.

- Lower impact of defecatory symptoms on a patient's daily life (but no evidence of this was found in China or Mexico).

- Several studies suggest that, among Afro-Caribbean Americans, compared with white individuals:

- Stool frequency is lower

- Prevalence of constipation higher

- In Latin America, constipation predominance is more frequent than diarrhea.

- Stool frequency appears to be greater in the Indian community as a whole-99\% passed stools once or more per day.
Fig 1. World map of IBS prevalence (2000-2004)

based on Rome II and III criteria, with Manning

criteria in parenthesis where available. Adapted

from: Neurogastroenterology and Motility

2005;17:317-24.

- In Mexico $70 \%$ have anxiety, 46\% depression and $40 \%$ both.

- In Mexico, IBS incurs a high economic impact due to a high use of medical resources.

- Clinical overlap of FD and IBS according to Rome III is very common in China.

- Psychological distress, life events and negative copying style may play important roles in the pathogenesis of IBS. Furthermore, these factors may also influence the individual's illness behavior and clinical outcome.

- Further studies need to establish:

- Importance of dietary differences among countries

- Different distribution of subtypes among countries

- Differences between urban and rural areas. A study in Israeli Bedouins, for example, suggested significant differences in IBS prevalence between desert Bedouins (5.8\%) and town Bedouins (9.4\%) using Rome II criteria.

\section{Diagnosis of IBS}

\section{Clinical history}

- Pattern of abdominal pain or discomfort :

- Chronic duration

- Type of pain: intermittent or continuous

- Previous pain episodes

- Localization of the pain-well localized pain is atypical

- Relief with defecation or passing of flatus

- Nocturnal pain is unusual and is considered a warning sign

- Other abdominal symptoms:

- Bloating

- Distension

- Borborygmi

- Flatulence

Note: Distension can be measured; bloating is a subjective feeling. As defined in English, bloating and distension may not share the same pathophysiology and should not be regarded as equivalent and interchangeable terms (although in some languages the terms may be represented by a single word). Nor does either necessarily imply that intestinal gas production is increased. 
- Nature of the associated bowel disturbance:

- Constipation

- Diarrhea

- Alternation

- Abnormalities of defecation:

- Diarrhea for $>2$ weeks

- Mucus in the feces

- Blood in stool

- Feeling of incomplete defecation

\section{Diagnostic cascade}

\section{Diagnostic cascade}

Level 1

- History, physical examination, exclusion of alarm symptoms, consideration of psychological factors

- Full blood count (FBC), erythrocyte sedimentation rate (ESR) or C-reactive protein (CRP), stool studies (white blood cells, ova, parasites, occult blood)

- Thyroid function, tissue transglutaminase (TTG) antibody

- Colonoscopy and biopsy

Level 2

- History, physical examination, exclusion of alarm symptoms, consideration of psychological factors

- FBC, ESR or CRP, stool studies, thyroid function

- Sigmoidoscopy

Level 3

- History, physical examination, exclusion of alarm symptoms, consideration of psychological factors

- FBC, ESR and stool examination

Cautionary note: The need for sigmoidoscopy and colonoscopy, should also be dictated by patient characteristics (presenting features, age, etc) and location ( i.e. whether in an area of high prevalence of irritable bowel disease, celiac disease, colon cancer or parasitosis or not). One could argue, for example, that a 21-year-old female with C-IBS-type symptoms and no alarm features merits, at most, celiac serology.

\section{IBS management}

\section{Introduction}

Note: With patient anxiety playing a key role, reassurance and education are of key importance.

There is no agreement on what is the best treatment for patients with moderate to severe symptoms. Bulking agents, loperamide and antidepressants come first.

The role of probiotics may further come to the fore but larger and high-quality randomized controlled trials are needed before more definite conclusions can be drawn about the benefit of, for example, Lactobacillus and Bifidobacterium.
However, clinical evidence of efficacy is beginning to emerge. The importance of a clear definition of strain selection, dose and viability is vital.

\section{Management cascade}

\section{Management cascade}

Level 1

- Reassurance, dietary and life-style review and counseling

- Add quality probiotic with proven efficacy

- Symptomatic treatment of:

- Pain with locally available antispasmodic, for more severely affected patients add low-dose tricyclic anti-depressant or SSRI

- Constipation with dietary measures and fiber supplementation progressing to osmotic laxatives or lactulose

- Diarrhea with bulking agents and simple antidiarrheals

- Consider psychological approaches (hypnotherapy, psychotherapy, group therapy) and consultation with a dietitian where indicated

- Add specific pharmacological agents where approved:

- Lubiprostone for C-IBS

- Rifaximin for diarrhea and bloating

- Alosetron for D-IBS

- Tegaserod for C-IBS

Level 2

- Reassurance, dietary and life-style review and counseling

- Add quality probiotic with proven efficacy

- Symptomatic treatment of:

- Pain with locally available antispasmodic, for more severely affected patients add low-dose tricyclic anti-depressant

- Constipation with dietary measures and fiber supplementation

- Diarrhea with bulking agents and simple antidiarrheals

Level 3

- Reassurance, dietary and life-style review and counseling

- Symptomatic treatment of:

- Pain with locally available antispasmodic

- Constipation with dietary measures and fiber supplementation

- Diarrhea with bulking agents and simple antidiarrheals 


\section{Gastroenterology on the Internet: IBS and PubMed}

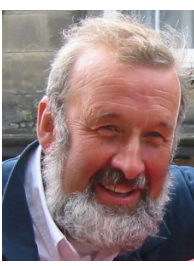

\author{
Drs. Justus Krabshuis
}

Highland Data, Tourtoirac, France

\section{Introduction}

Nobody knows what causes irritable bowel syndrome (IBS) - it is functional, and its etiology is unknown. It cannot be explained, but that does not stop us ... we can describe it and then we can treat the symptoms. Recent research shows that fiber, antispasmodics, and peppermint oil are more effective than placebo in the treatment of irritable bowel syndrome (PMID 19008265). Antidepressants are also effective in the treatment of IBS. There is less highquality evidence on the routine use of psychological therapies in IBS, but available data suggest these may be of comparable efficacy (PMID 19001059). And probiotics? Well, the future of probiotics may be bright, as the most recent systematic review in the journal Gut suggests (PMID 19091823).

IBS is to be the subject of the 2009 World Digestive Health Day (WDHD). As its contribution to WDHD, the World Gastroenterology Organisation (WGO) has just completed a guideline on IBS-an IBS review team has looked at the latest in IBS management, and in line with WGO publishing policy there are cascades for colleagues in resource constrained areas. WGO guidelines are not "resource-blind"- see the latest version when it becomes available at http://www.worldgastroenterology.org/ global-guidelines.html.

So let's look at the online landscape-reminding ourselves of some useful PubMed features and as usual reflecting on a few controversial questions, this time about if and how different cultures can affect the presence and reporting of IBS symptoms. Finally, I want to share with you a fine PubMed-based initiative from Latin America-a virtual gastroenterology library with IBS as its first example.

\section{Looking for IBS in PubMed}

As a librarian, it took me a while to understand the difference between irritable bowel syndrome (IBS) and inflammatory bowel disease (IBD). So, not surprisingly, I turned to PubMed. Let's look under "PubMed services" in the left-hand navigation bar and click on "MeSH database." You can always get a definition of any MeSH term by going to the PubMed thesaurus, Medical Subject Headings (MeSH) at: http://www.ncbi. $\mathrm{nlm}$.nih.gov/sites/entrez?db=mesh. Type in the word which you think best describes what you are looking for, choosing a unique word rather than a common word, for example "irritable."

There are two MeSH terms that include the word 'irritable': irritable mood and irritable bowel syndrome: The latter is defined as "A disorder with chronic or recurrent colonic symptoms without a clearcut etiology. This condition is characterized by chronic or recurrent abdominal pain, bloating, mucus in feces, and an erratic disturbance of defection. Year introduced: 2004."
Now click on "irritable bowel syndrome," and you find several interesting items. MeSH recognizes the following synonyms (called "entry terms"):

- Irritable bowel syndromes

- Syndrome, irritable bowel

- Syndromes, irritable bowel

- Colon, irritable

- Colitis, mucous

- Colitides, mucous

- Mucous colitides

- Mucous colitis

I also note that the term was introduced in 2004. How, one wonders, was the concept indexed before 2004? A quick check of the indexing history shows:

- Colonic diseases (1967-1970)

- Colonic diseases, functional (1970-2003)

What does this mean? Well, anything resembling what today we call IBS would have been indexed under "colonic diseases" in the period 19671970 and under "colonic diseases, functional" in the period 1970-2003.

This is a nuisance for searchers. If you are in an evidence-based frame of mind and looking for IBS trials going back further than 2003, for example for the last 10 years, you will now have to stop and think a little. After all, you now need two strategies-one for randomized controlled trials (RCTs) 
published between 1999 and 2003 and another for RCTs published from 2004 to today.

Apart from building the right strategy, there is an additional problem. "Colonic diseases, functional" is a very broad concept, and in the period 1970-2003 it would have been used for a number of varying conditions, not just IBS. So when searching for IBS over the last 10 years by combining the two indexing terms used for IBS over the last 10 years you will find that many of the "hits" are not relevant. The precision of the search goes down. There is no way around this other than "re-indexing," and that is impossible.

Now you can search for IBS in PubMed - let's have some fun and move on to more controversial issues.

\section{Is there an "East-West" issue? Shall we "sack Rome"?}

The prevalence of irritable bowe syndrome in any defined population depends on which criteria (for prevalence) are applied: the Kruis scoring system, the Manning criteria, or the ROME-I, ROME-II, or ROMEIII criteria (from the Rome Foundation at: http://www.theromefoundation. org). Not all criteria are validated for all countries. Some countries are "still" using ROME-I, while others are already (!) using ROME-III. Does this sound a little like academic oneupmanship to you?

These are "process-centered" criteria. A recent study from India (PMID 18541934) argues that we should be mindful of "patient-centered" criteria. Key symptoms such as diarrhea, constipation, bloating, and pain are subjective, and in India these are not captured adequately by the Rome criteria. The study suggests that the local culture in different countries may inform which symptoms are reported, and how.

So is IBS a Western disease? No; probably not. Is IBS studied from a predominantly Western point of viewthat is to say, described with Westerndeveloped criteria? Yes, definitely!
Is this a good thing? "For whom?" | hear you ask. And, speaking as a true librarian, I would answer: "It depends on who you read."

With IBS research driven by available resources, there is (understandably, I think), a natural tendency for the West to "self-cite." This world-for example, the world of the Rome Foundation, set up in the 1980s to develop the study of functional gastrointestinal disorders, represents the elite of the IBS research community. A glance at the Rome Foundation committees provides a "Who's Who" in IBS - it consists almost entirely of physicians from the Western world.

Do we not need more representation from non-Western experts here? Medical science, especially, does not play out in a sociocultural vacuum, whether East or West. Key symptoms such as diarrhea, constipation, bloating, and pain may be experienced differently. The typical western IBS patient is often a young woman, but this gender characteristic has not been reproduced in recent studies in Asia. Most patients with IBS in India were middle-aged men in the Indian study mentioned above, and abdominal pain or discomfort (an essential ROME-III criterion), though frequent, were not universal.

Besides, what about the influence of diet? If we assume that different dietary patterns have varying effects on colonic motility and other physiological phenomena relevant to IBS, is it possible that the Rome-III criteria may only "work" in populations in which dietary patterns are more or less similar? Is this not what the old ceteris paribus (other things being equal) criterion is all about? Let me leave you with a stirring quote about Rome and functional gastrointestinal disorders (FGIDs) that I found in Neurogastroenterology and Motility (2007;19:793-7; PMID 17883430): "It is, therefore, time to marvel and be thankful for what Rome has left us (the Coliseum, its culture, the precision of Latin, and an appreciation of the prevalence of FGIDs and their impact), and move on! It is time to sack Rome and follow the Hun."

\section{Does culture matter?}

Could the Rome Foundation not start an "IBS and Culture" committee? At the same time, could scientific and medical publishers not start a journal on comparative gastroenterology? A journal focusing on "nature-nurture" issues in key gastroenterology topics? Alternatively, it could be called the "Journal of Cultural Gastroenterology." Comparison is one of the oldest methods in science and is truly heuristic.

Let's look again at the recent large IBS enquiry conducted by the Indian Society of Gastroenterology Task Force (ISG), published in the Indian Journal of Gastroenterology in 2008 (PMID 18541934; for the full text, click here). A commentary is published in the same issue under the title "Defining IBS in India: a brave new world" (PMID 18541928; for the full text, click here).

And while we are talking "culture"what exactly does this mean? If the Rome-III criteria suggest that a certain percentage of Indian men have diarrhea-predominant IBS, but the self-reporting does not back this up ... what then? And anyway (I am taking this from the commentary mentioned earlier; click here), "to base outcomes on a questionable recall of a subjective rating of discomfort makes the Rome criteria highly unreliable." The comment compliments the ISG study for its courage in "not allowing itself to be straight-jacketed by Westerndirected criteria' (i.e., Kruis, Manning, and Rome).

I know we should always try to stand on each others' shoulders when exploring a topic (meaning we should take account of the existing evidence), but there is an issue of "false avenues" and paradigms that have come to an end, and there are questions of ethnicity and culture and geography as discussed in the literature (e.g. PMID 


\section{$\theta \ominus \theta \quad$ Virtual Room of Gastroenterology \\ (4) (C) C ( $D$ (http://presentaciones.110mb.com/ibs/ \\ 红 \\ Virtual Library of Gastroenterology}

Irritable Bowel Syndrome: It is defined by PubMed/MeSH Database as "a disorder with chronic or recurrent colonic symptoms without a clearcut etiology. This condition is characterized by chronic or recurrent abdominal pain, bloating, mucus in feces, and an erratic disturbance of defecation".

\begin{tabular}{|c|c|c|c|}
\hline Irritable Bowel Syndrome & $\begin{array}{l}\text { Abstracts published } \\
\text { in the last } 5 \text { years }\end{array}$ & $\begin{array}{c}\text { Free full text } \\
\text { published } \\
\text { in the last } 5 \text { years }\end{array}$ & Definitions of terms \\
\hline Diagnosis & E & 日 & What is.. \\
\hline Epidemiology & 目 & 日 & What is... \\
\hline Etiology & 且 & E & What is.. \\
\hline Ethnology & 目 & 目 & What is.. \\
\hline Genetics & 且 & 日 & What is.. \\
\hline Pathology & 且 & E & What is.. \\
\hline Prevention and Control & 且 & 日 & What is.. \\
\hline Therapy & 日 & 日 & What is.. \\
\hline Evidence & & & What is.. \\
\hline Meta-Analysis & 目 & E & \\
\hline Randomized Controlled Trial & 且 & 旦 & \\
\hline Practice Guideline & 且 & 日 & \\
\hline Cascades & 日 & 日 & What is... \\
\hline
\end{tabular}

This section is an automated search interface for bibliographic information and free full text in real time for a variety of topics related to Irritable Bowel Syndrome.

To the right of each term you will find two icons. Clicking on the red icon $\mathbf{E}$ gives you the latest citations and abstracts of the relevant literature generated by your search terms. If you click on the green icon $\#$ you get all the 'freely available' full text articles generated by your search terms. Pubmed search results are always displayed in chronological order with the most recently published articles first.

15771752 and PMID 15916618). Try a search in PubMed for "irritable bowel syndrome" and "ethnic groups." The hyperlink below has stored the strategy:

- Irritable Bowel Syndrome[mh] AND Ethnic groups[mh]

Now come the important questions: Do you, the reader, feel that IBS presents differently in different parts of the world? Does culture have an effect on symptom reporting? Does culture matter? How?

\section{The Spinelli-Henderson IBS Library}

So, what can PubMed do for our IBS information needs? There are several ways we can stay informed about IBS research, and the SpinelliHenderson Virtual Library for IBS is the most creative one I have seen to date (click on the hyperlinked title above to access the library at http:// presentaciones. $110 \mathrm{mb}$.com/ibs/). Its functionality is based on PubMed's feature of allowing a search strategy to be captured as a web address, and in this way-hyperlinking from our self-designed icons-we can build a virtual library with automatic searches based on embedded search strategies. Clicking on the red icon (for "practice guideline"), for example, searches PubMed for publications indexed with both "irritable bowel disease" and "practice guideline." Clicking on the green icon (for IBS and diagnosis) links to full-text articles dealing with IBS and diagnosis. The site is, of course, experimental and entirely thanks to the voluntary efforts of two Latin American professors of medicine. Their initiative deserves wide recognition for creativity in using advanced PubMed features. Needless to say, this approach can also be easily applied in other areas of medicine.

Have a look and let me know what you think. Or e-mail your suggestions and ideas to Prof. Osvaldo Spinelli in Argentina (ospineli@gmail.com) or Prof. Eduardo Henderson in Uruguay (eduardo.henderson@gmail.com). Happy searching —and remember, IBS is the topic for World Digestive Health Day 2009. 


\section{GASTRO 2009 — the place to be}

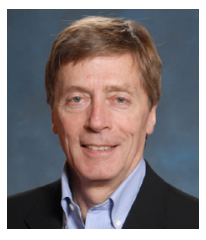

Michael Farthing, MD

Vice-Chancellor University of Sussex, Bristol, UK

As Chair of the Program Committee for GASTRO 2009 and as a member of the British Society of Gastroenterology, I would like to encourage all readers of WGN to make a note of the dates for the meeting (21-25 November 2009). This will be the largest and most comprehensive scientific meeting of gastroenterologists, hepatologists, endoscopists, surgeons, pediatricians, imagers, and basic scientists that has ever taken place for our specialty in Europe. The program has both breadth and depth, as it has been produced by a consortium of organizations-namely, the United European Gastroenterology Federation (UEGF), World

Gastroenterology Organisation (WGO), Organisation Mondiale d'Endoscopie Digestive/World Organization of Digestive Endoscopy (OMED), and British Society of Gastroenterology (BSG). The meeting will attract participants from every continent and will deliver the highest-quality program imaginable.

GASTRO 2009 will span 5 days.

The first two will involve a postgraduate teaching program, which will begin with a plenary on the management of inflammatory bowel disease (IBD) and close with a plenary session on the management of gastrointestinal bleeding, between which four parallel courses on endoscopy, hepatology, gastroenterology and, for the first time, gastrointestinal surgery will be "sandwiched."
The core program will begin with an opening plenary session, which will be a mix of state-of-the-art lectures and a selection of the "best abstracts" submitted to the meeting. There will be live endoscopy on each day, coming from India, London, and Rome. The scientific program will be approximately evenly divided between symposia, providing updates on important topics such as IBD, Barrett's esophagus, viral hepatitis, colorectal cancer, and important developments in endoscopy and imaging, and free paper sessions consisting of oral presentations of new research. In addition, there will be a daily "clinics in gastroenterology and hepatology" session in which problem clinical cases will be presented and discussed by a team of experts, a basic science workshop, and eight lunch sessions each day in which participants will be able to discuss common clinical problems with experts. Throughout the meeting, there will be a young clinicians' program that will bring gastroenterologists in training together from around the world.

It goes without saying that the Program Committee has been aware from the start that this is a global gastroenterology meeting, and the choice of symposia, topics, and speakers has therefore taken this into account to ensure that we address issues of global relevance.

London will, of course, offer an unbeatable range of social and cultural opportunities, as will the social program being planned to run alongside the scientific meeting. More details are available on the GASTRO 2009 website www.gastro2009.org. I look forward to seeing you there. 

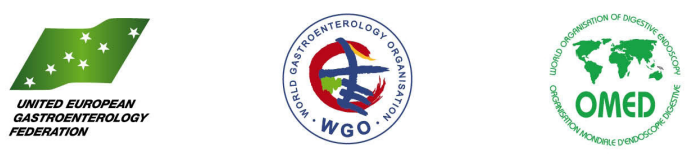

\section{GASTRO 2009 UEGW / WCOG: London program highlights}

GASTRO 2009, London—a new meeting for the new millennium—will provide an extensive program including a range of symposia on clinical updates, the world's best gastrointestinal and liver science, and excellent training opportunities for established and nascent gastroenterologists. At least $50 \%$ of the core program will consist of original research communications, and there will also be clinical case sessions, lunch sessions, and a poster exhibition. The Program Committee for GASTRO 2009 is committed to delivering:

- A world class array of new science in gastroenterology and hepatology

- High-quality updates on the frontiers of global clinical practice

- Interdisciplinary symposia on new approaches to diagnosis and treatment

- Live endoscopy from around the world each day

- A major emphasis on innovative, technical advances in the noninvasive management of gastrointestinal and hepatic disorders

- Overriding emphasis on the importance of addressing both research and clinical practice issues at the global level

- Eight commissioned working team reports

- New research workshops on each day of the core program

- A full two-day postgraduate program that incorporates gastroenterology, hepatology, endoscopy, surgery, imaging and other diagnostic modalities. Participants will purchase a "passport" to move around the various options that will be running in parallel, to allow them to "pick'n mix" according to their needs and interests.

A more detailed format description is available in the Preliminary Program, which can be downloaded at www.gastro2009.org. Those wishing to receive a copy of the Preliminary Program for GASTRO 2009 should contact the GASTRO 2009 Congress Secretariat at secretariat@gastro2009.org, regular updates on GASTRO 2009 can be signed up for on the GASTRO 2009 mailing list at www.gastro2009.org.

\section{Fun Run, GASTRO 2009 UEGW / WCOG, London Sunday, November 22, 2009}

Have some fun-join our run! Support a medical charity while improving your health! The Public Affairs Committee is pleased to announce the GASTRO 2009 Fun Run, a charitable event to be held on the occasion of GASTRO 2009 in London. Delegates are invited to register for the Fun Run on Sunday, November 22. The attractive 5-km running track starts and finishes near the congress venue.

General information:

Date/time: Sunday, November 222009 at 10 a.m.

Place: ExCeL London

Distance: $5 \mathrm{~km}$

Registration fee: $€ 10.00$

Participation is limited to a maximum of 1000 starters.

The registration fee includes:

Runner's shirt

Start number and rental of timing chip

Free runner's breakfast

Finisher medal

Personalized finisher certificate
Registration process: Available only online at www. gastro2009.org. If you have your own timing chip (which you want to use), please have its code ready for the online registration process.

Payment process: Only credit card payments are accepted. If you do not have a credit card, please contact dm\&c (Destination Management \& Consulting Europe) directly at funrun09@dm-and-c.at.

The registration fee of $€ 10.00$ will be deemed to be a donation and will be handed over during the award ceremony to the appointed organization.

Please note the following important deadlines for GASTRO 2009:

- Registration: 15 May 2009, end of early registration; 16 October 2009, end of late registration,

- Abstract submission: 8 June 2009, deadline for abstract and clinical case submission. Deadline for late-breaking abstract submission: 17 July 2009. 


\section{Interview with David Carr-Locke}

WGN: I understand that you were not always a gastroenterologist. Please tell us about your training and how you came to develop a specialist interest in therapeutic endoscopy.

Dr. Carr-Locke: I received almost no exposure to gastroenterology as a medical student, except from a surgical perspective. My first two experiences as a house officer (intern) in the British system were with a physician and surgeon interested in gastroenterology, where I was exposed to endoscopy in 1972 and 1973. As a student, however, I had enjoyed obstetrics so much that I thought this would be my career path and I took a residency position in $\mathrm{Ob} /$ Gyn. Laparoscopy was in its infancy at that time, but something drove me to return to the medical specialties to broaden my horizons. This coincided with the start of Britain's newest medical school, in Leicester in 1975. The Dean invited me to join the Department of Medicine as the only lecturer in gastroenterology. This allowed me to develop basic gastrointestinal endoscopy skills; I was subsequently introduced to endoscopic retrograde cholangiopancreatography (ERCP) in Leicester in 1974. I designed and built three endoscopy units in Leicester hospitals, where I gained practical and research experience and developed an essential association with surgeons.

WGN: You were part of the "brain drain" from Britain. Looking back, how do you feel about having left the UK to work in the USA?

DCL: By the time I left the UK in 1989, the National Health Service (NHS) had become a very frustrating environment in which to work as a specialist dependent on expensive equipment and wishing to conduct research and

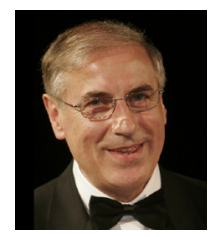

David L. Carr-Locke, MD

Director of The Endoscopy Institute Brigham \& Women's Hospital, Boston, MA, USA

develop new technology. As I started to travel to international conferences, I acquired a global perspective on our specialty. Invitations to look at working in academic endoscopy units in the U.S. in the late 1980s were not hard to accept. I was considered overly ambitious and a traitor to the NHS by many in the UK, but I knew I could never achieve my potential there. I do not regret my decision to move to the U.S.

WGN: You have been involved in the development of ERCP from the early days. You were an investigator in the first prospective, randomized clinical trial of ERCP with sphincterotomy for gallstone pancreatitis. Please share with us your recollections of the early days of therapeutic ERCP.

DCL: I shall always recall our first ERCP in 1974. We were not permitted to perform the entire procedure in the radiology department! We were required to find the papilla and cannulate it in our endoscopy unit, then move the patient to radiology to complete the ERCP! That only happened once. Our duodenoscopes were narrow-caliber, with small channels; as there was no effort to make them electrically insulated, many of us received shocks and burns around the optical eyepiece on a regular basis (there were no video endoscopes then). I performed over 500 ERCPs in our first year. After the terrifying experience of my first sphincterotomy and stone extraction (with only basket catheters available), it was clear to me that this would become the standard method for treating bile duct stones. Plastic stents were not available until 1980. Guide wires, sphincterotomes, catheters, and baskets were all reused until they broke. What a difference today, 30 years on!

WGN: With the advent of helical computed tomography, magnetic resonance cholangiopancreatography (MRCP) and endoscopic ultrasonography (EUS), there have been dark murmurings that "ERCP is dead." How do you respond to this?

DCL: Noninvasive imaging was primitive when ERCP was introduced; now it is superlative. The need for diagnostic cholangiography and pancreatography has diminished and almost, but not quite, disappeared. However, the range and indications for therapeutic procedures have grown exponentially. As in many areas of gastroenterology, we can only make a significant impact on disease with therapy rather than improved diagnostic methods alone. ERCP now plays a fundamental role in the management of ampullary, pancreatic, and biliary disease. The need for expertise is the highest it has ever been, and there seems little chance that this will die.

WGN: You have traveled the world as an ambassador for American gastroenterology and gastrointestinal endoscopy. Can you share any "war stories" with us about adventures you have had in the process?

DCL: I cannot express enough the honor it is to be thought of as an international ambassador for our specialty. Since the first time my brother took me climbing in the Austrian Tyrol at age 16, I have wanted to travel, and have been privileged with the opportunity to do so in my professional life. One remembers incredible sights-from the Great Wall of China to the Great Barrier Reef, from the 
Pyramids to the Grand Canyon, from the Himalayas to Machu Picchu—with all of their associated customs, cultures, and food. Unquestionably, however, the most prominent memory is of people and hospitality. International travel is not always glamorous, and stamina is a useful asset. One of the first live demonstrations with which I was involved lasted over 12 hours in $90^{\circ}$ heat, and at the end there were still many patients waiting to be treated!

To those critics of live endoscopy courses and procedures performed by visiting faculty, I would say that I have witnessed the tremendous stimulus that such courses have had on local endoscopy and the demand for education and training that follows. When working in less than ideal circumstances, surrounded by crowds of people talking in languages other than your own, and with a myriad of distractions, it is essential to maintain one's focus on the patient and ensure the best outcome.

\section{WGN: Congratulations on your} recent honor, the 2007 Schindler Award from the American Society for Gastrointestinal Endoscopy (ASGE). Can you tell us about the award and what it means to you?

\section{DCL: The Rudolph Schindler Award} represents the highest honor the ASGE can bestow on one of its members for services to the profession. The list of 53 previous honorees reads like the Who's Who of endoscopy. So to be included in this list is incredible. I am enormously proud to have been considered for this award. In many ways, it recognizes the work my colleagues and I have accomplished over the last 30 years.

Some consider this award as marking the end of a career, but for me it is a stimulus to change gears and start again.
WGN: As someone who has seen more of the world than most of us, what is your impression of the global need for gastroenterology and gastrointestinal endoscopy? How do you see WGO's role in addressing global issues?

DCL: Diseases of the gastrointestinal tract and associated organs are very prominent in world health. It is clear that in the developing world, there is a tremendous need for specialist services, training, and equipment. Many governmental and nongovernmental private, domestic, and international organizations, including the WGO, have begun to change the delivery of gastrointestinal health care through education and training. We have seen the tremendous impact that diagnostic and therapeutic endoscopy have had in the West. We have a responsibility to address the needs of health care in the developing world by any and all means. My international activities have played a rather small part in this huge process, but the WGO has made a commitment to addressing these global needs and should be commended for it. I shall continue to devote a significant part of my professional life to spreading the art and science of gastrointestinal endoscopy wherever I am able to do so.

\section{WGN: What major advances in} endoscopy should we expect in the next 5-10 years?

\section{DCL: Gastrointestinal endoscopy is} likely to undergo some radical changes in the next decade, but this will occur in different ways and at different rates in different parts of the world. We shall see the impact of colon cancer screening in parts of the world that have yet to implement programs such as those that have impacted colon cancer in North America and Europe.
We shall also see the effect of wider availability of therapeutic endoscopy throughout the developing world. We shall also see the introduction of new endoscopy technologies, new imaging methodologies, and the ability to image pathology in real time, which will have a dramatic effect on how we use endoscopy. Our ability to perform real surgical procedures not only within the gastrointestinal lumen but outside it as well has become a reality. Undoubtedly, we shall see the growth of a new type of hybrid interventional endoscopist capable of performing a wide range of endoscopic and surgical procedures as part of an interventional team. These are certainly very exciting times to be involved in any aspect of endoscopy.

WGN: Finally, what advice would you give to a gastroenterology fellow who is considering endoscopy as a specialist interest?

DCL: All gastroenterology fellows learn the basics of endoscopy in their training, but a few have a natural talent to go above and beyond the majority, and these become the next generation of highly skilled endoscopists who will continue the tradition of advancing the frontiers and training others. The career of a gastroenterologist starting out today will truly be dominated by minimally invasive approaches to disease management. The potential for combining endoscopy with developments in human genomics, nanotechnology, drug and other therapeutic delivery tools, and approaches to common problems that no longer require a skin incision will make the world of endoscopy a completely different place 20 years from now. 


\section{Great mentors Steven Silvis and Jack Vennes}
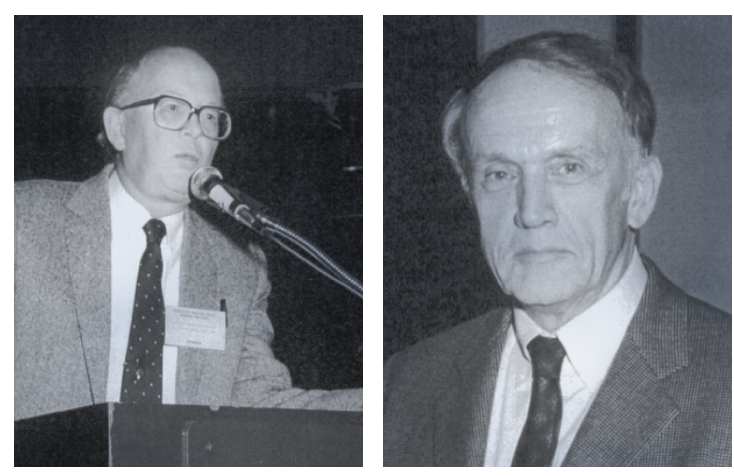

Prof. Steven Silvis (left) and Prof. Jack Vennes.

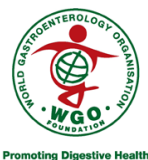

WGO Scholar Awards

Every year the WGO Foundation will honour and celebrate mentors who have made significant contributions to gastroenterology on a global scale by recognising them as a "Master of the WGO". A special "Masters of the WGO Fund" has been established to award WGO Mentor Scholar Awards to promising up-and-coming gastroenterologists in developing low-resource countries to give them the financial support to further their careers in digestive disease. This Scholar Award is uniquely directed toward supporting those talented individuals who are committed to furthering the care of digestive disorders in their home country and their training will be specifically tailored to optimally prepare them for their future. The Scholar Award will provide training at a WGO Training Center in their particular geographical region. Since the establishment of the WGO Training Centers, 1100 trainees from developing countries have benefited and we are working diligently to raise funds in support of additional awards and trainees. To find out more, please visit www.wgofoundation.org
As a Fellow in Gastroenterology at the University of Minnesota in the early 1980s (1981-84), my research project was on bile acid metabolism. With a background in pathology and molecular biology, I had hooked up with Dr. Russ(ell) Hanson, a renowned bile acid researcher, for my fellowship research project. I was on the fast track to becoming a gastroenterologist with a laboratory interest in bile acid regulation. However, two-thirds of the way into my research year, Dr. Hanson tragically died in a motor vehicle accident while on a weekend hunting trip. Dr. Hanson's research was so specialized that no one at the University of Minnesota was able to take over his laboratory. The National Institutes of Health and other funding bodies "froze" their grants, so dozens of my precious assays remained (literally) frozen in a $-80{ }^{\circ} \mathrm{C}$ refrigerator and never saw the mass spectrometer they had been destined for. Russ Hanson's untimely death brought my research to a screeching halt, and I walked the halls (and the banks of the Mississippi) wondering, what comes next?

Two senior physicians at the Minneapolis Veterans' Medical Center, Dr. Steve(n) Silvis and Dr. Jack Vennes came to me with an offer: stay an extra year at the end of your (2-year) fellowship and we'll train you up in ERCP. Amazingly (in retrospect), I asked for the weekend to think it over. Fortunately, I said "Yes, please," and (as they say) the rest is history. By blind good luck, I had stumbled onto a hidden treasure: two of the most amazing mentors a fellow could ever have. Steve and Jack had the patience of Job (more than I will ever have!) and enough comfort in their own abilities and stature that they never wanted the limelight. Like all great mentors, they took great pleasure in the achievements of their trainees. And there were a lot of them. Steve and Jack trained a whole generation of ERCP endoscopists.

Sadly, they are both now deceased, but their memory lives on. Cook, Inc., has generously endowed a memorial lecture given during the ASGE Plenary Session at Digestive Diseases Week honoring Steve Silvis and Jack Vennes. Always ones to push the envelope, Steve and Jack would be happy to see that the first two annual lectures have been on natural orifice transluminal endoscopic surgery (NOTES) - the latest endoscopic technology on the block. 


\section{Interview with Tom Finn \\ President of Global Health Care for Procter \& Gamble}

WGN: Procter \& Gamble (P\&G)

has partnered with the World

Gastroenterology Organisation (WGO)

to support World Digestive Health Day, the WGO's annual digestive health campaign. The focus of the campaign this year is irritable bowel syndrome (IBS). Can you tell us what P\&G is doing in the IBS field?

Tom Finn: First, I would like to share that $P \& G$ is proud to be working with the WGO in support of World Digestive Health Day and the WGO IBS Task Force. We recognize that irritable bowel syndrome is a global digestive health issue, impairing the quality of life and work productivity of an estimated $7-10 \%$ of the world's population. We applaud WGO's efforts to raise the awareness of and standard of care for this global health problem.

$P \& G$ has one of the strongest portfolios of leadership brands in consumer health and wellness and is a leader in digestive health care. We have conducted a number of preclinical and clinical studies to better understand IBS and to look for effective treatment options. As a result of this work, we have launched a new probiotic, Bifidobacterium infantis 35624, also known as Bifantis ${ }^{\circledR}$, that has been clinically proven in two placebocontrolled trials to be effective against all of the cardinal symptoms of IBS.

The results of these studies have been published in Gastroenterology and in the American Journal of Gastroenterology. In addition, we are working to advance the understanding of IBS and to promote overall digestive health and wellness.

WGN: Through World Digestive Health Day, $P \& G$ is reaching out to patients to encourage them to educate themselves about their digestive health. What is the role of companies in educating patients about health?

TF: At P\&G, we believe it is important to educate patients about their condition, helping them to understand what triggers their symptoms and what lifestyle changes they might undertake to manage their health. We do this in a number of ways, which include providing disease information with our products, maintaining web sites where patients can both obtain disease information and join patient communities to share their stories and provide support to each other, and supporting the work of nonprofit organizations such as the WGO.

WGN: Has P\&G partnered with nonprofit organizations before? If so, tell us a little bit about the projects.

TF: P\&G's purpose is to improve the everyday lives of the world's consumers. We fulfill this purpose in many waysthrough P\&G brands, first and foremost, but also through our support of humanitarian, educational, and social cause efforts. At the corporate level, $P \& G$ has committed to focus on the development of children in need through our global cause, P\&G Live, Learn and Thrive $^{\mathrm{TM}}$. Millions of children around the world live in heartbreaking conditions.

By strengthening current programs, introducing new ones, and focusing P\&G expertise and technologies on this critical need, we can improve the future for these children. P\&G Live, Learn and Thrive comes to life through dozens of programs around the world, including its signature program, Children's Safe Drinking Water. P\&G partners with a number of nonprofit organizations on many of our awareness campaigns.

WGN: How can nonprofit and for-profit organizations work together?

TF: The key to working together is for each to recognize the other's needs. For example, companies must realize that a nonprofit organization cannot endorse a product without losing credibility and hence effectiveness in helping to advance the field. At the same time, nonprofits must recognize that companies are focused where they have a business interest. By being aware of each other's needs, both can work together for the benefit of the patient.

WGN: Tell us a little bit about what you do at P\&G, and what you will be doing on World Digestive Health Day_29 May 2009.

TF: I am the President of Global Health Care for Procter \& Gamble. I have responsibility for our personal healthcare and pharmaceutical businesses worldwide. On World Digestive Health Day, it will be my pleasure to host the WGO Summit Task Force on "The Global Aspects of IBS." I'm looking forward to welcoming all of the task force members to our Mason Business Center to kick off the start of this important work.

As part of World Digestive Health Day (WDHD) 2009, there will be a WGO Summit Task Force meeting on "The Global Aspects of IBS." This summit will bring together leading IBS experts from around the world to assess the status of IBS prevalence, impact, and management in different societies and cultures. In keeping with the mission of the World Gastroenterology Organisation, this summit aims to draw attention to the global prevalence of IBS, areas of need, and the less resource-privileged.

The IBS Summit will take place at various times during 2009, with the first meeting being held on WDHD itself, 29 May, in Cincinnati. Further virtual meetings will take place over subsequent months, leading to the completion of an enduring document and the presentation of the Task Force's findings at a special satellite symposium at GASTRO 2009 in London. The Summit Task Force is commissioned with completing a consensus statement and educational tool for distribution to all 109 WGO national gastroenterology societies and for general dissemination.

We are proud to announce that Procter \& Gamble shares the WGO's passion and mission for World Digestive Health Day and has kindly agreed to support the WGO Summit Task Force. 


\section{GASTRO 2009 UEGW/WCOG, London}

H. 1 .

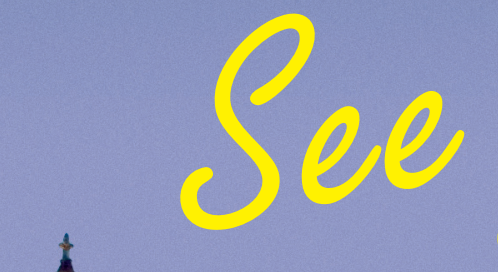
you II
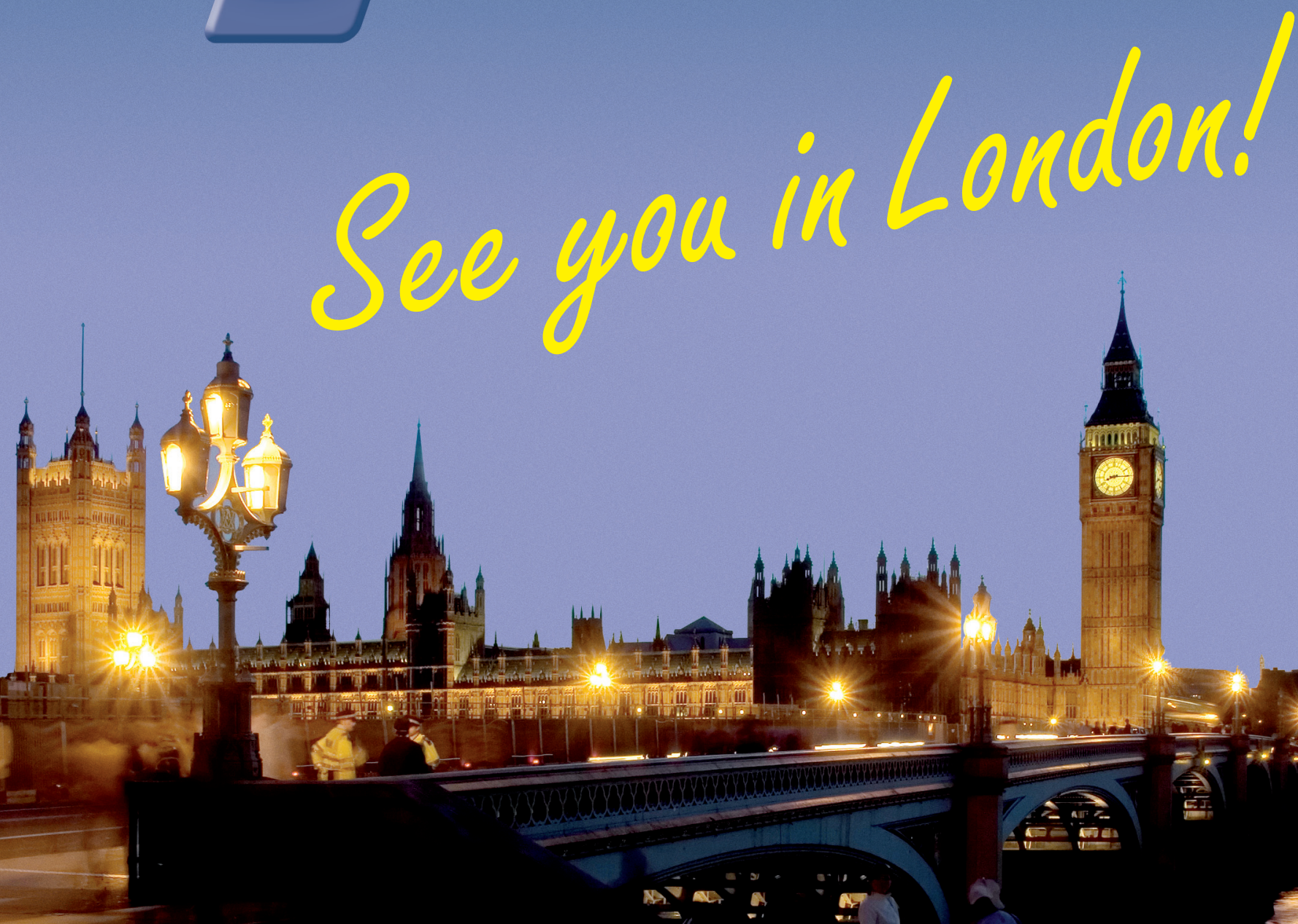